\title{
CRF-R2 and the Heterosynaptic Regulation of VTA Glutamate during Reinstatement of Cocaine Seeking
}

\author{
Courtney L. Williams, William C. Buchta, and ${ }^{1}$ Arthur C. Riegel \\ Medical University of South Carolina, Charleston, South Carolina 29425
}

\begin{abstract}
Stress can reinstate cocaine seeking through an interaction between the stress hormone corticotropin releasing factor (CRF) and glutamate release onto dopamine neurons in the ventral tegmental area (VTA). To better understand the underlying causes, synaptic mechanisms were investigated in brain slices from rats. In control tissue, EPSCs displayed concentration-dependent, bimodal responses to CRF potentiation at low concentrations (3-100 nM) and attenuation at higher concentrations ( $300 \mathrm{~nm}$ ). EPSC potentiation and attenuation were mediated by CRF-R1 and CRF-R2 receptor subtypes, respectively, localized to presynaptic terminals. The CRF-R2 attenuation was blocked by the GABA-B receptor antagonist CGP55843. Additional recordings of GABA-A IPSCs showed CRF-R2 activation-facilitated presynaptic release of GABA, suggesting that CRF-R2 may regulate glutamate release via heterosynaptic facilitation of GABA synapses. After chronic cocaine self-administration and extinction training, the sensitivity of glutamate and GABA receptors was unchanged. However, the ability of CRF-R2 agonists to depress EPSCs and potentiate IPSCs was diminished. After yohimbine plus cue reinstatement, the actions of CRF-R2 on GABA and glutamate release were reversed. CRF-R2 activation increased EPSCs as a result of a reduction of tonic GABA-dependent inhibition. After reinstatement, application of the A1 adenosine antagonist 1,3-dipropyl-8-cyclopentylxanthine increased GABA tone to inhibit the CRF-R2 action. Blockade of GABA-B receptors prevented both the CRF-R2 increase in EPSCs and the attenuation produced by 1,3-dipropyl-8-cyclopentylxanthine. These studies demonstrate that presynaptic CRF-R1/R2 tightly regulate glutamate transmission in the VTA via a concerted, heterosynaptic manner that may become altered by stress-related pathologies, such as addiction.
\end{abstract}

Key words: addiction; CRF; dopamine; GABA; glutamate; stress

\section{Introduction}

Glutamate innervation of the ventral tegmental area (VTA) strongly modulates cue-based learning processes (Chen et al., 2008). The recent link between glutamate release in the VTA and the stress hormone corticotrophin releasing factor (CRF) is particularly interesting given the well-known impact of environmental stressors on dopaminergic output (Bannon et al., 1983; Deutch and Roth, 1990). However, it remains unclear exactly how CRF regulates VTA function and whether individual CRF receptor subtypes play unique roles in this regulation.

CRF has been reported to mediate homosynaptic and heterosynaptic plasticity (Gallagher et al., 2008). There are two principle types of CRF receptors, CRF receptor subtype-1 (CRF-R1) and subtype-2 (CRF-R2), both of which stimulate Gs-coupled

Received Feb. 25, 2013; revised June 9, 2014; accepted June 24, 2014.

Author contributions: A.C.R. designed research;C.L.W. and A.C.R. performed research; C.L.W., W.C.B., and A.C.R. analyzed data; C.L.W., W.C.B., and A.C.R. wrote the paper.

This work was supported by National Institute on Drug Abuse Grants R01-DA033342 to A.C.R. and P30DA028811 as well as Medical University of South Carolina Neurobiology of Addiction Research Center Pilot Grant P50DA015369. We thank Drs. Ford, Beckstead, Dumont, and Williams for their helpful comments.

The authors declare no competing financial interests.

Correspondence should be addressed to Dr. Arthur C. Riegel, Department of Neurosciences, Medical University of South Carolina, 410C Basic Science Building, 173 Ashley Avenue, Charleston, SC 29425-5100. E-mail: Riegel@musc.edu.

C.L. Williams' present address: Oregon Health and Science University, Portland, Oregon 97239.

DOI:10.1523/JNEUROSCI.0911-13.2014

Copyright $\odot 2014$ the authors $\quad 0270-6474 / 14 / 3410402-13 \$ 15.00 / 0$ signaling and activate protein kinase A (PKA). Genetic studies broadly associate CRF-R1 with axiogenesis and CRF-R2 with anxiolysis (Bale et al., 2000; Kishimoto et al., 2000; Risbrough et al., 2004). CRF-R1, which plays a stimulatory role in stress responsivity, can facilitate glutamate signaling and support LTP (Ji and Neugebauer, 2007; Gallagher et al., 2008). Conversely, CRF$\mathrm{R} 2$, which dampens stress sensitivity or promotes recovery from stressful situations, can depress glutamate responses (Timpl et al., 1998; Bale et al., 2000; Coste et al., 2000). In the amygdala, heterosynaptic depression of glutamate release involves a CRF-R2 mediated increase in GABA transmission and subsequent activation of presynaptic GABA-B receptors (Fu and Neugebauer, 2008). GABA-B receptors also regulate glutamate transmission in the VTA (Manzoni and Williams, 1999). This raises the possibility that CRF-R2 receptors in the VTA may indirectly regulate glutamate via changes in GABA transmission. However, this has not been directly demonstrated physiologically, nor is it known how coincident activation of presynaptic CRF-R1/R2 may affect glutamate release and dopamine neuron excitability.

Many studies of CRF-mediated plasticity in the VTA have focused on excitatory synapses. Transient recruitment of these terminals is required for learning to self-administer natural rewards (Chen et al., 2008). In the context of drug selfadministration, VTA infusion of CRF increases excitatory transmission and drug seeking only in cocaine-experienced animals (Wang et al., 2005). Furthermore, reinstatement of cocaine seek- 
ing by foot shock is dependent on CRF signaling in the VTA (Wang et al., 2005). However the underlying mechanism remains unknown, as both CRF-R1 and CRF-R2 have been causally implicated (Wang et al., 2007; Blacktop et al., 2011). Given that a balance of excitation and inhibition shapes neuronal excitability, knowledge of how CRF influences transmission in the VTA is necessary to predict the functional impact of this peptide on dopaminergic signaling. Here, we investigate actions of CRF at excitatory and inhibitory synapses in the VTA. We demonstrate that activation of CRF-R1 increases glutamate transmission, whereas CRF-R2 increases GABA release to attenuate glutamate release via activation of presynaptic GABA-B receptors. After cocaine self-administration and yohimbine plus cue reinstatement, the CRF-R2 function reversed and increased EPSCs by reducing tonic GABA-dependent inhibition. In previous studies, it was shown that repeated exposure to cocaine elevates extracellular adenosine in the VTA (Fiorillo and Williams, 2000). After reinstatement, blockade of $\mathrm{Al}$ adenosine receptors with the antagonist 3-dipropyl-8-cyclopentylxanthine (DPCPX) increased GABA tone to inhibit the CRF-R2 potentiation of EPSCs. Blockade of GABA-B receptors prevented both the CRF-R2 increase in EPSCs and the attenuation produced by DPCPX. These findings support a heterosynaptic association between CRF and stress-induced changes in VTA function. Dysregulation of this synaptic crosstalk may play a role in addiction as well as other neuropsychiatric disorders.

\section{Materials and Methods}

All protocols were conducted under National Institutes of Health Guidelines using the National Institutes of Health handbook Animals in Research and were approved by the Institutional Animal Care and Use Committee (Medical University of South Carolina, Charleston, SC).

Recordings. Brain slices were prepared from adult male rats (P65P100) as described previously (Riegel and Lupica, 2004; Riegel and Williams, 2008). Briefly, after rapid decapitation, brains were removed, blocked, and placed in a vibratome (Leica) containing ice-cold ACSF solution (126 mm NaCl, $2.5 \mathrm{~mm} \mathrm{KCl,} 1.2 \mathrm{~mm} \mathrm{MgCl}_{2}, 1.4 \mathrm{~mm} \mathrm{NaH}{ }_{2} \mathrm{PO}_{4}$, $25 \mathrm{~mm} \mathrm{NaHCO}, 11 \mathrm{~mm}$ D-glucose, $0.4 \mathrm{~mm}$ ascorbate, and $0.01 \mathrm{~mm}$ MK801). Horizontal slices $(220 \mu \mathrm{m})$ containing the ventral tegmental area were prepared and stored in oxygenated ACSF $\left(95 \% \mathrm{O}_{2}-5 \% \mathrm{CO}_{2} ; 34^{\circ} \mathrm{C}\right)$.

Whole-cell recordings were made using multiclamp $700 \mathrm{~B}$ amplifiers (Molecular Devices). Neurons were voltage clamped at $\sim-60 \mathrm{mV}$ using 1-2 $\mathrm{M} \Omega$ pipettes. Pipette internal solution contained $115 \mathrm{~mm}$ K-methylsulfate, $20 \mathrm{~mm} \mathrm{NaCl}, 1.5 \mathrm{~mm} \mathrm{MgCl}_{2}$, $2.5 \mathrm{~mm}$ HEPES, 2 mм ATP, $0.3 \mathrm{~mm}$ GTP, and $0.1 \mathrm{~mm}$ EGTA (pH 7.3; 265-270 mOsm). Series resistance $(<10 \mathrm{M} \Omega)$ was compensated at $80 \%$. Dopamine neurons resided $<150 \mu \mathrm{m}$ from the lateral or medial side of the terminal nucleus of the accessory optic tract. This is a region rich in dopamine cell bodies (Wolfart et al., 2001; Ford et al., 2006). Recordings from neurons in this region displayed pacemaker firing $(1-2 \mathrm{~Hz})$, broad action potentials $(\geq 1.2 \mathrm{~ms})$, and large $\mathrm{H}$ currents $(>300 \mathrm{pA}$ at $-120 \mathrm{mV})$ (Williams and Fiorillo, 1998; Wolfart et al., 2001; Ford et al., 2006). These cells also display a hyperpolarizing mGluR-mediated current carried by the sK channel that is observed only in dopamine neurons in midbrain slices (Marino et al., 2001). Although there have been reports of difficulties in identifying dopamine neurons, the combination of the area in which the recordings were made coupled with the criteria used to identify the electrophysiological characteristic of dopamine cells indicates that the results are based on recordings from dopamine cells. Recordings were collected using AxoGraph X (AxoGraph Scientific) and filtered at $1-2 \mathrm{kHz}$, digitized at $2-5 \mathrm{kHz}$.

To evoke synaptic currents (30\% of maximum, baseline), stimuli (100-150 $\mu$ s duration) were delivered through bipolar tungsten electrodes (FHC) placed near $(50 \mu \mathrm{m})$ the cell body. Cells were stimulated at $0.033 \mathrm{~Hz}$ for all experiments and continued during drug application to monitor the time course of action. For paired-pulse experiments, two stimuli were applied at an interval of $50 \mathrm{~ms}$ (Manabe et al., 1993), and the paired-pulse ratio (PPR) was calculated by dividing the amplitude of the EPSC or IPSC evoked by the second stimulus by the amplitude of the first EPSC or IPSC evoked by the first stimulus. A change in the PPR is thought to result from the alteration in transmitter release caused by a presynaptic mechanism (Manabe et al., 1993). Evoked EPSC and IPSC amplitudes were measured by averaging a $5 \mathrm{~ms}$ window around the peak and subtracting the average value obtained during a $5 \mathrm{~ms}$ window immediately before the stimulus. All experiments were done in the presence of the dopamine $\mathrm{D}_{2}$ receptor antagonist sulpiride $(200 \mathrm{~nm})$ and the $\mathrm{D} 1$ antagonist SCH-23390 (1 $\mu \mathrm{M})$. For some experiments, the tissue was incubated with apamin (100 nM). For IPSC recordings, NBQX $(5 \mu \mathrm{M})$ and CGP $55845(10 \mu \mathrm{M})$ were included to block AMPA and GABA-B receptors, respectively. Spontaneous miniature EPSCs (mEPSCs) were recorded in the presence of TTX (200 nM). mEPSC amplitude and frequency were measured using Axograph and a sliding algorithm template. The threshold for detection was $15 \mathrm{pA}$.

Drugs. Drugs were applied to the slice by superfusion. Peptide drugs were purchased from American Peptide Company and applied in ACSF containing bestatin and thiorphan (Sigma). K41498, NBI27914, antisauvagine-30, and CP154156 were purchased from Tocris Bioscience. Apamin and eticlopride were purchased from Sigma. K-methylsulfate was purchased from Fisher Chemicals. All other compounds were purchased from Abcam (formerly Ascent Scientific).

Data analysis. Group data are presented as the mean \pm SEM in all cases. Statistical analyses were done with $t$ tests, ANOVAs, or the Kolmogorov-Smirnov performed using a critical probability of $p<0.05$ (Prism version 4.01, GraphPad Software). Post hoc analysis (NewmanKeuls or Bonferroni's post-test) was performed only when an ANOVA yielded a significant $(p<0.05)$ main effect.

Cocaine self-administration. All experiments were conducted according to the National Institutes of Health Guidelines for the Care and Use of Laboratory Animals. Rats were allowed a minimum of $3 \mathrm{~d}$ to acclimate to the rat vivarium with ad libitum access to food and water before surgery. Surgery was conducted as previously published (Fuchs et al., 2004; Feltenstein and See, 2006). Briefly, rats were anesthetized with ketamine $(66 \mathrm{mg} / \mathrm{kg})$, xylazine $(1.33 \mathrm{mg} / \mathrm{kg})$, and equithesin $(0.5 \mathrm{ml} / \mathrm{kg}$ with a solution of $9.72 \mathrm{mg} / \mathrm{ml}$ pentobarbital sodium, $42.5 \mathrm{mg} / \mathrm{ml}$ chloral hydrate, and $21.3 \mathrm{mg} / \mathrm{ml}$ magnesium sulfate heptahydrate dissolved in a $44 \%$ propylene glycol, $10 \%$ ethanol solution, i.p.), implanted with indwelling jugular catheters, and allowed to recover for $7 \mathrm{~d}$. Animals began behavioral training $7 \mathrm{~d}$ after surgery. All self-administration experiments were conducted in standard operant chambers fitted with two retractable levers, a stimulus light, and speakers linked to computerized data collection software program (MED-PC, Med Associates).

Rats were placed into these chambers and allowed to press the active lever to receive an infusion of cocaine $(0.25 \mathrm{mg} / \mathrm{kg}$ over $4 \mathrm{~s})$, paired with a light and tone cue, and followed by a $20 \mathrm{~s}$ time out, during which responses were counted but did not result in cocaine infusion. Inactive lever presses produced no programmed response. Each training session lasted $2 \mathrm{~h}$, after which animals were returned to their home cages. Cocaine self-administration (Cocaine-SA) continued until animals reached criteria ( $10 \mathrm{~d}$ of $>25$ active lever presses). Extinction training began after animals reached training criteria, during which a press on either lever produced no response. Some animals underwent reinstatement testing after extinction training (criteria for extinction: at least $7 \mathrm{~d}$, with $<25$ active lever presses on the final 2 consecutive days). These animals received either injections of saline or yohimbine and were placed into their operant chambers. During reinstatement testing, active lever presses initiated a light and tone cue. Brain slices were prepared from rats undergoing cocaine self-administration $(n=16)$, self-administration with extinction $(n=13)$, reinstatement testing $(n=16)$, and their matching yoked saline controls ( $n=14$ per group).

\section{Results}

\section{CRF potentiates AMPA receptor currents}

We examined whether activation of CRF receptors altered excitatory signals in the VTA. Whole-cell voltage-clamp recordings were acquired from dopamine neurons in acute slices of rat mid- 
brain, and synaptic currents were recorded in response to synaptic stimulation by an extracellular stimulating electrode (Fig. 1A). The synaptic activation of AMPA receptors resulted in an inward EPSC that could be completely blocked by NBQX (5 $\mu \mathrm{M})$. After brief superfusion of CRF (100 nM; $10 \mathrm{~min}$ ), there was a significant increase in the amplitude of EPSCs (CRF: $54 \pm 11 \%$ increase relative to baseline, $t_{(4)}=10.21, p=0.0003$; Fig. $1 B, C$ ), which peaked at $\sim 8-12 \mathrm{~min}$ and occurred without alteration in the holding current (control: $31 \pm 3.8 \mathrm{pA}$; CRF: $34 \pm 4 \mathrm{pA} ; t_{(11)}=0.3512$, not significant). A second agonist specific for CRF receptors, urocortin (UCN; $100 \mathrm{nM}$ ), produced a similar potentiation of EPSCs (UCN: $50 \pm 18 \%$ increase relative to baseline, $t_{(11)}=0.3923, p<0.0001$; maximum effect of CRF vs UCN: $t_{(9)}=1.358, p=$ 0.1038, not significant; Fig. 1C). Application of UCN alone did not alter the holding current (control: $63 \pm 10 \mathrm{pA}$; UCN: $70 \pm 11 \mathrm{pA} ; t_{(5)} p=0.7906$, not significant). After washout of CRF or UCN ( $\sim 30 \mathrm{~min}$ ) with ACSF alone, EPSCs recovered to near control levels (CRF: $5 \pm$ $7 \%$ increase relative to baseline, $t_{(8)} p=$ 0.2081, not significant; UCN: $7 \pm 11 \%$ increase relative to baseline, $p=0.8881$; data not shown). In each experiment, the stimulus was adjusted such that the amplitude of the baseline EPSC was $<30 \%$ of the maximum such that the CRF- or UCN-induced increases in the current did not saturate the conductance.

\section{Bimodal and concentration-dependent actions of CRF}

The concentration dependence of CRF was evaluated over a range of 3-300 nM. At lower concentrations (3-30 nM), CRF generated a slow increase of the EPSC amplitude that developed over a prolonged period and failed to plateau even after $40 \mathrm{~min}(3$ nM CRF at 32-37 min: $18 \pm 7 \%$ increase over baseline; $30 \mathrm{~nm} \mathrm{CRF}$ at 32-37 min: $47 \pm 8 \%$ increase over baseline; Fig. $1 D, E)$. At 100 $\mathrm{nM}$, the CRF-potentiation peaked earlier (at 15-20 min: $51 \pm$ $11 \%$ increase relative to baseline; Fig. $1 D, E$ ), and thereafter declined toward baseline despite the continued presence of CRF (32-37 min: $97.94 \pm 1.95 \%$ of baseline; Fig. 1 D, E). At $300 \mathrm{~nm}$, the CRF potentiation peaked at $5-10 \mathrm{~min}(20 \pm 9 \%$ increase relative to baseline; Fig. $1 D, E)$ and then declined below baseline levels (CRF response at 32-37 min: $68.26 \pm 0.44 \%$ of baseline). ANOVA (two-way) revealed a significant effect of concentration $\left(F_{(3,82)}=459.0, p<0.0001\right)$, time (early at $15-20 \mathrm{~min}$ vs late at 32-37 min; $\left.F_{(1,82)}=54.11, p<0.0001\right)$, and a significant interaction of concentration $\times$ time $\left(F_{(3,82)}=192.9, p<0.0001\right)$. Post hoc tests (Bonferroni multiple comparisons) confirmed differences at early versus late times for the $3 \mathrm{nM}\left(t_{(82)}=3.378, p<0.01\right), 30$ $\mathrm{nM}\left(t_{(82)}=8.218, p<0.0001\right), 100 \mathrm{nM}\left(t_{(82)}=25.65, p<0.0001\right)$, and $300 \mathrm{nM}\left(t_{(82)}=7.880, p<0.0001\right)$ concentrations (Fig. $\left.1 E\right)$. Thus, in addition to its ability to potentiate EPSCs, CRF at slightly higher concentrations also attenuates EPSCs. In all subsequent experi-
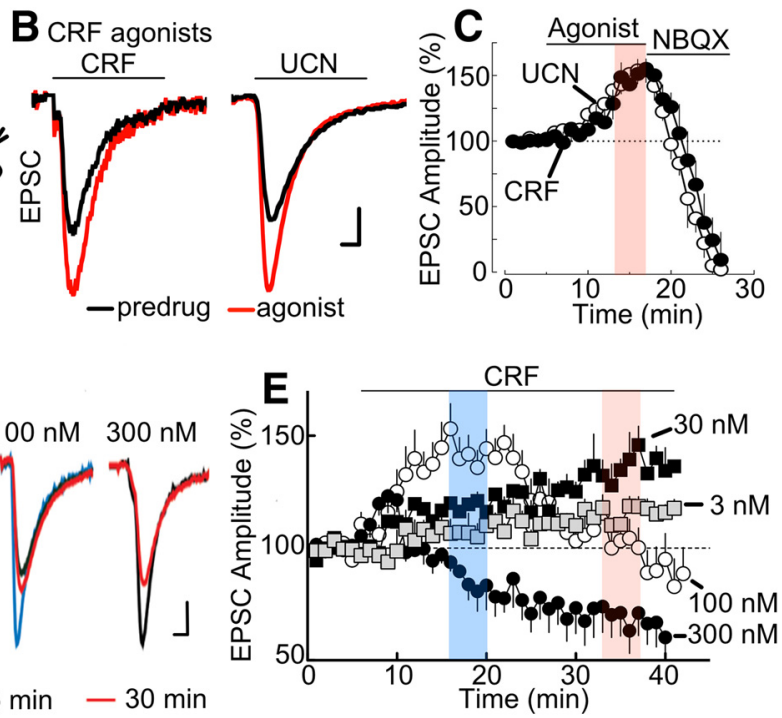

Figure 1. CRF-R activation potentiates glutamate EPSCs in a concentration-dependent manner. $\boldsymbol{A}$, Left, Simplified VTA circuit 6 cells; 3 rats). The steady state of the potentiation produced by application of (RF-R agonists is highlighted in red. In this and in of application of CRF at $3 \mathrm{~nm}$ (30-40 min), $30 \mathrm{~nm}$ (30-40 min), $100 \mathrm{~nm}$ (15-20 min), and $300 \mathrm{~nm}$ (30-40 min). Calibration: 100 pA, ( inhibited EPSCs during later time periods (30-40 min). A high dose of CRF (300 nm) showed an attenuation of EPSCs. In this and other plots, CRF was applied at 100 nm to evaluate both the "early" (RF potentiation ( 12-15 min of application, blue) and "late" CRF attenuation ( $~ 20$ min of application, red). E, Sample size for CRF experiments: $3 \mathrm{~nm}(n=8$ cells; 4 rats), $30 \mathrm{~nm}(n=9$ cells; 5 rats), $100 \mathrm{~nm}$ ( $n=18$ cells; 10 rats), and $300 \mathrm{~nm}$ ( $n=14$ cells; 7 rats).

ments, CRF (100 nM) was applied for $25 \mathrm{~min}$ to examine the opposing actions of CRF during early (10-15 min) and late (20-25 $\mathrm{min})$ application.

\section{CRF-R1 and CRF-R2 mediate opposing actions of CRF}

To determine which receptor subtype(s) modulate AMPA receptor EPSCs, CRF was tested in the presence of specific antagonists for CRF-R1 (CP154156 or NBI27914) or CRF-R2 (K41498 or antisauvagine-30) (for summary, see Fig. 2A). Activation of CRF-R1 by coapplication of CRF (100 nM) and K41498 (200 nM) increased EPSC amplitude (CRF + K41498: $54 \pm 23 \%$ increase relative to baseline; $t_{(5)}=38.52, p<0.0001$; Fig. $\left.2 B 1, B 2\right)$. Similar experiments with a different CRF-R2 antagonist, antisauvagine30 (ASV-30, $200 \mathrm{~nm}$; incubation $>10 \mathrm{~min}$ ), produced analogous responses (CRF + ASV: $52 \pm 19 \%$ increase relative to baseline; $t_{(5)}=22.84, p<0.0001$; Fig. 2B2). In contrast, activation of CRF-R2 by coapplication of CRF (100 nM) and NBI27914 (200 $\mathrm{nM})$ attenuated EPSC amplitude (CRF + NBI: $44 \pm 9 \%$ decrease relative to baseline; $t_{(5)}=33.67, p<0.0001$; Fig. 2 B1,B2). Experiments conducted with CRF plus CP154156 (200 nM; incubation $>15 \mathrm{~min}$ ), a different CRF-R1 antagonist, yielded similar results $\left(\mathrm{CRF}+\mathrm{CP}: 42 \pm 12 \%\right.$ decrease relative to baseline; $t_{(5)}=$ 23.28, $p<0.0001$; Fig. 2B2). The CRF-R1 and CRF-R2 antagonists did not alter the holding current (control vs K41498, $t_{(5)}=$ 0.2221 , not significant; control vs ASV-30, $t_{(6)}=0.3216$, not significant; control, vs NBI27914, $t_{(5)}=0.23347$, not significant; control vs CP154156; $t_{(5)}=0.1991$, not significant). 

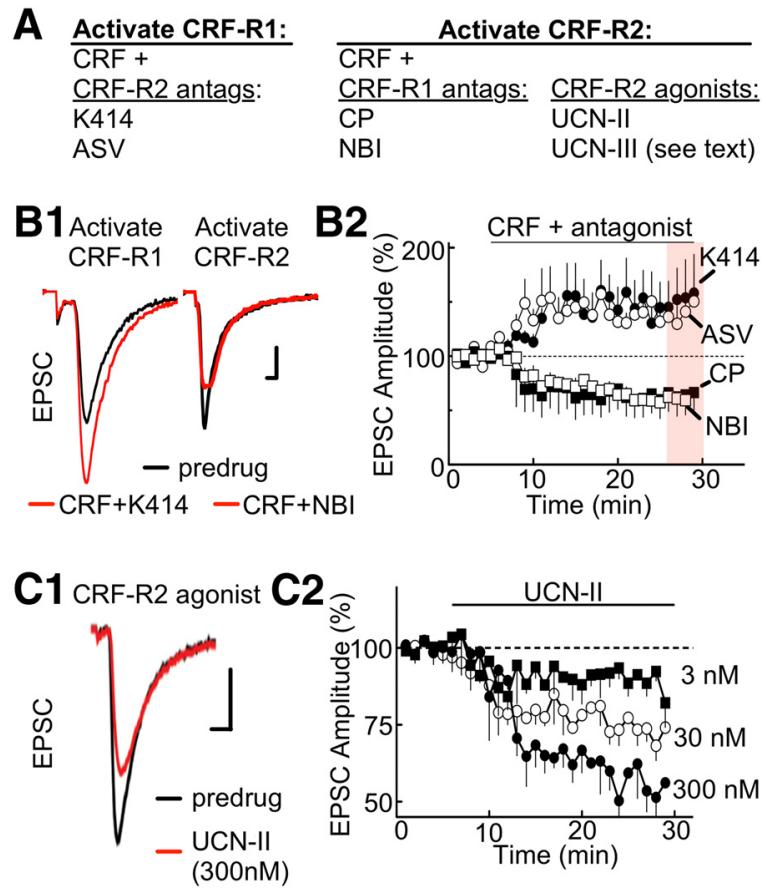

Figure 2. CRF-R1 activation potentiates EPSCS, and CRF-R2 attenuates ESPCS. A, Summary table listing the subtype selectivity for CRF receptor agonists and antagonists. The experimental conditions for selective activation of (RF-R1/R2 are described. B1, Stimulus-evoked EPSCs are increased by CRF-R1 activation (left) but decreased by CRF-R2 activation (right). To activate the

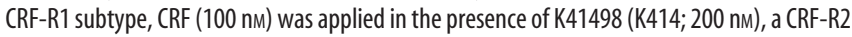
antagonist. To activate the CRF-R2 subtype, CRF (100 nM) was applied in the presence of the CRF-R1 antagonist NBI27914 (NBI; 200 nm). Calibration: 100 pA, 1 ms. B2, Summarized time course of EPSC amplitude (\% of baseline, mean \pm SEM) illustrating the CRF-R1 potentiation and CRF-R2 attenuation with additional antagonists included for CRF-R1 (CP-154526, CP; 200 nm) and (RF-R2 (antisauvagine-30, ASV-30; $200 \mathrm{~nm}$ ). Sample size for K41498, ASV, NBI, and CP154156 experiments: $n=6$ cells at 3 or 4 rats per drug. C1, Sample stimulus-evoked EPSCs are attenuated by direct activation of (RF-R2 by UCN-II ( $300 \mathrm{nM}$ ). Calibration (all traces): $100 \mathrm{pA}$, $1 \mathrm{~ms}$. C2, Summarized time course of EPSC amplitude (\% of baseline, mean \pm SEM) showing the concentration dependence of UCN-II (3-300 nm; sample size: $n=8$ cells and 5 rats per concentration).

The actions of CRF-R2 were evaluated further with the specific agonists UCN-II (UCN-2) and UCN-III (UCN-3). Individual ANOVAs (one-way repeated measures) indicated a significant, dose-dependent effect of UCN-II on EPSCs $\left(F_{(2,56)}=\right.$ $30.12, p<0.0001)$. Lower concentrations of UCN-II decreased EPSCs (relative to baseline) to a smaller extent ( $3 \mathrm{~nm} \mathrm{UCN-II} \mathrm{at}$ 20 min: $8 \pm 4 \%$; $30 \mathrm{nM} \mathrm{UCN}-\mathrm{II}$ at 25-30 min: $23 \pm 6 \%$; post hoc Bonferroni Multiple Test of $3 \mathrm{~nm}$ vs $30 \mathrm{~nm}: t_{(56)}=4.018, p<$ 0.001; Fig. 2C2). At $300 \mathrm{~nm}$, UCN-II decreased EPSCs (UCN-II at 25-30 min; $48 \pm 9 \%$ decrease relative to baseline; post hoc Bonferroni Test of $30 \mathrm{~nm}$ vs $300 \mathrm{~nm}: t_{(56)}=3.741, p<0.01$; Fig. 2 C1,C2). Application of UCN-III at $300 \mathrm{~nm}$ produced a similar reduction in EPSCs (UCN-III at 25-30 min: $44 \pm 14 \%$ decrease relative to baseline, $t_{(4)}=4.312, p=0.03$, data not shown). Together, these results suggest that CRF potentiates EPSCs through activation of CRF-R1 and attenuates EPSCs through activation of CRF-R2.

\section{CRF-R1/R2 are presynaptic receptors}

The site of action of CRF was investigated in two ways. First, we measured the effects of CRF and specific CRF-R1/2 antagonists on the PPR to determine whether CRF alters the release probability of glutamate. Manipulations that influence presynaptic release generally alter paired-pulse plasticity in a predictable manner. Activation of CRF-R2 with application of CRF (100 nM; $12 \mathrm{~min}$ ) in the presence of a CRF-R1 antagonist (NBI27914, 100 nM) shifted the PPR toward facilitation (inhibition of EPSCs: $39 \pm 18 \%$; increase in PPR, $27 \pm 9 \% ; t_{(5)}=7.456 ; p=0.0007$; Fig. $3 A$ ). Similar experiments using CRF (100 nM; $12 \mathrm{~min}$ ) with a CRF-R2 antagonist (K41498) to activate CRF-R1 receptors selectively produced opposite responses. That is, EPSCs increased (mean potentiation of EPSC: $30 \pm 9 \%$; Fig. $3 B$ ) and the PPR moved further toward depression (mean decrease in PPR: $27 \pm$ $11 \% ; t_{(5)}=4.452 ; p=0.007$; Fig. $3 B$ ). The second method used to determine the site of the CRF action was by measuring the effect of CRF on the frequency of spontaneous EPSCs (Fig. 3C). CRF produced bimodal actions on the frequency of spontaneous EPSCs and shifted the interevent interval distribution curve significantly to the left at $10 \mathrm{~min}$ and then back to the right at $20 \mathrm{~min}$ of application $(p=0.0018$, Kolmogorov-Smirnov test; Fig. $3 D 1)$. On average, the frequency of EPSCs shifted from $1.86 \mathrm{~Hz}$ to $3.8 \mathrm{~Hz}$ at $10 \mathrm{~min}$ (baseline vs $10 \mathrm{~min}: t_{(7)}=13.72 ; p<0.0001$; Fig. 3D2) and back to $2.14 \mathrm{~Hz}$ at $20 \mathrm{~min}$ (10 vs $20 \mathrm{~min}: t_{(7)}=$ 2.997; $p=0.020$; Fig. 3D2). However, there was no significant change in the amplitude of spontaneous EPSCs $(p=0.34$, Kolmogorov-Smirnov test; Fig. 3D1; from $12.1 \pm 2.2$ pA to $15.8 \pm$ $3.2 \mathrm{pA}$ at $10 \mathrm{~min} ; t_{(7)}=2.250 ; p=0.06$, not significant; Fig. $3 D 2$; and $11.2 \pm 3.5 \mathrm{pA}$ at $20 \mathrm{~min} ; t_{(7)}=1.423 ; p=0.1977$, not significant; Fig. 3D2). Under control (no drug) conditions, neither the frequency nor the amplitude of spontaneous EPSCs measurably changed (frequency: $2.1 \pm 0.3 \mathrm{~Hz}$ at $10 \mathrm{~min}, 1.97 \pm 0.6$ $\mathrm{Hz}$ at $25 \mathrm{~min}, t_{(7)}=1.528 ; p=0.1705$, not significant; amplitude: $15.4 \pm 4.2 \mathrm{~Hz}$ at $10 \mathrm{~min}, 12.7 \pm 3.6 \mathrm{~Hz}$ at $25 \mathrm{~min}, t_{(7)}=1.871 ; p=$ 0.1036 , not significant; data not shown). The slow temporal response of CRF to alter the frequency of spontaneous EPSCs is consistent with our previous report, showing this large (41 amino acid) molecule is slow to penetrate the brain slice and occupy receptors (Riegel and Williams, 2008). Thus, CRF receptors of both subtypes located on presynaptic terminals regulate the release probability of glutamate onto dopamine neurons.

Additional control experiments measuring spontaneous mEPSCs in the presence of TTX further support this conclusion. Under these conditions, CRF increased the frequency of spontaneous mEPSCs at $10 \mathrm{~min}$; however, the late-stage CRF attenuation at 20 min was absent (CRF baseline vs $10 \mathrm{~min}: 1.7-3.5 \mathrm{~Hz}$, $t_{(6)}=38.94, p<0.0001$; CRF 10-20 min: 3.5-3.7 Hz, $t_{(6)}=1.261$, not significant; data not shown). Reflecting this, the interevent interval distribution curve shifted left at $10 \mathrm{~min}$ but did not shift right at $20 \mathrm{~min}$ of application (Kolmogorov-Smirnov test: control vs $10 \mathrm{~min}, p=0.001 ; 10 \mathrm{~min}$ vs $20 \mathrm{~min}, p=0.82)$. A possible explanation for the observed CRF-R2 attenuation in the frequency of spontaneous EPSCs could involve a heterosynaptic mechanism (i.e., activation of GABA terminals by CRF-R2).

\section{CRF-R2 attenuation requires metabotropic GABA- $\mathrm{B}$ receptors}

Earlier studies indicate that presynaptic GABA-B receptors regulate AMPA EPSCs recorded in dopamine neurons (Manzoni and Williams, 1999). It was also recently reported that, in the amygdala, CRF attenuates EPSCs indirectly, by facilitating GABA release and subsequently stimulating GABA-B receptors on the glutamatergic terminals ( $\mathrm{Fu}$ and Neugebauer, 2008). We investigated this mechanism of CRF inhibition in the VTA in two steps (Fig. $4 A, C)$. In slices from naive rats, CRF (100 nM) was applied in the presence of the GABA-B receptor antagonist CGP55845 (CGP $10 \mu \mathrm{M}$; Fig. 4A). This treatment did not significantly alter the early CRF-R1-mediated potentiation in EPSCs; responses 
A1 Activate CRF-R2
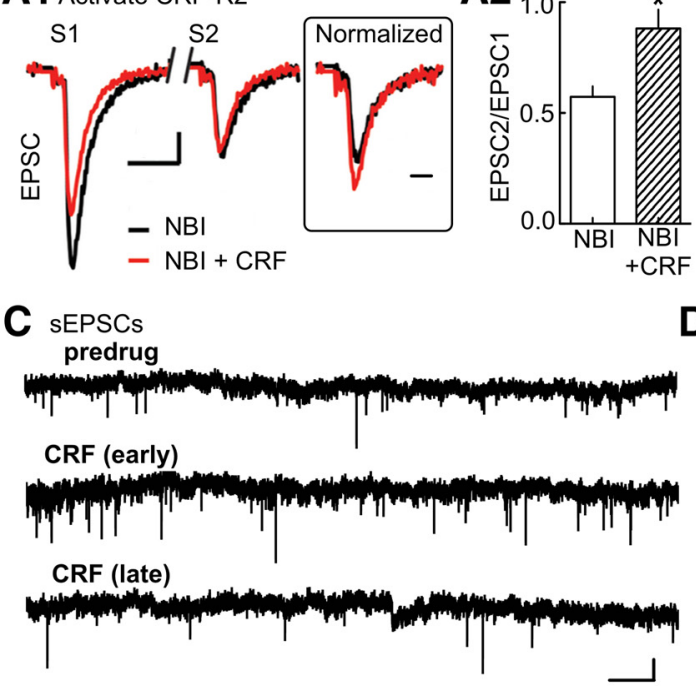

A2
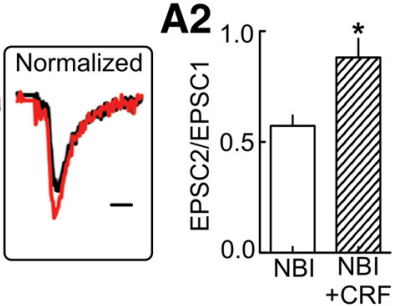

B1 Activate CRF-R1
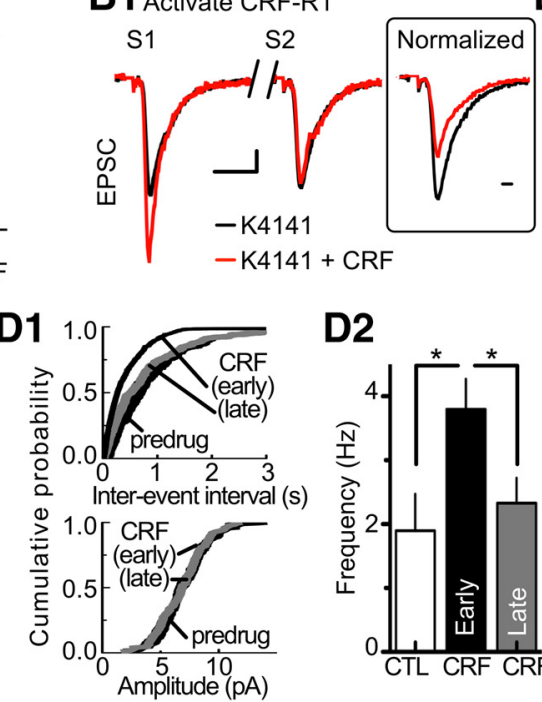

D2

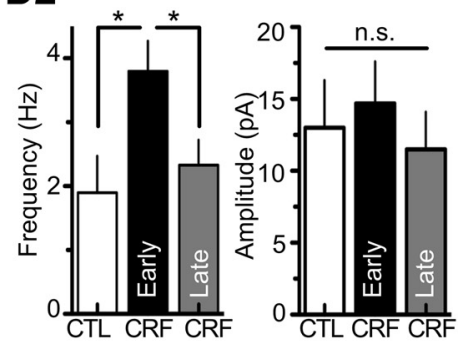

Figure 3. CRF-R1/R2 are located on presynaptic terminals. A1, Sample EPSCs evoked by paired-pulse stimulation indicate that inhibition of the EPSC by CRF-R2 activation is accompanied by a facilitation of the PPR. CRF-R2 was activated by CRF (100 nm) applied in the presence of the CRF-R1 antagonist NBI27914 (200 nm). Inset, The second EPSC (S2) after normalizing the amplitude of the EPSC evoked by the first stimulus (S1). Calibration: S1/S2, 50 pA, $5 \mathrm{~ms}$; inset, $1 \mathrm{~ms}$. A2, Bar graph of the PPR (EPSC2/EPSC1) summarizing the effects of CRF-R2 activation. ${ }^{*} p=0.0007$ (sample size: $n=18$ cells, 9 rats). B1, Sample EPSCs evoked by paired-pulse stimulation show that CRF-R1 activation potentiates EPSC and shifts the PPR toward depression. CRF-R1 was activated by CRF (100 nm) applied in the presence of the (RF-R2 antagonist K41498 (200 nm). Inset, The normalized EPSC (S2). Calibration: S1/S2, 100 pA, 5 ms; inset, 1 ms. B2, Bar graph of the PPR summarizing the effects of CRF-R1 activation. ${ }^{*} p=0.007$ ( $n=12$ cells, 7 rats). C, Raw current traces illustrating the early-phase potentiation and late-phase attenuation of sEPSC by CRF (100 nm). Calibration: 20 pA, $1 \mathrm{~s}$. D1, Top, The interevent interval distribution curve of sEPSC was altered by CRF (100 nm). In the (RF early phase, the curve shifted to the left and shifted back to the right in the late phase (Kolmogorov-Smirnov test, $p=0.0018$ ). Bottom, cumulative probability plot for the amplitude of sEPSCs was not altered by (RF (Kolmogorov-Smirnov test, $p=0.34$ ). D2, Bar graphs of average sEPSC frequency (left) and amplitude (right) showing the effect of early and late CRF application: control (CTL) vs CRF (early) frequency: ${ }^{*} p<0.0001 ;$ CTL vs CRF (late) frequency: * $p=0.020$; CTL vs CRF (early) amplitude: $p=0.0687$, not significant; CTL vs CRF (late) amplitude: $p=0.1977$, not significant; sample size: $n=8$ cells, 4 rats per group.

peaked within $10 \mathrm{~min}$ and resembled the CRF challenge without CGP55845 (CRF: $48 \pm 9 \%$ increase relative to baseline, $t_{(7)}=$ 4.66, $p=0.0023$; Fig. 4B1,B2; CRF+CGP: $53 \pm 15 \%$ increase relative to baseline, $t_{(7)}=18.48, p=0.0001$; Fig. $\left.4 B 1, B 2\right)$. However, with inclusion of CGP55845, the late-phase CRF attenuation was replaced with a potentiation that persisted at $20 \mathrm{~min}$ of application, similar to what was observed with specific CRF-R2 antagonists (CRF: $5 \pm 11 \%$ decrease relative to baseline, $t_{(7)}=$ 1.557; $p=0.1634$, not significant; CRF + CGP: $53 \pm 15 \%$ increase relative to baseline, $t_{(7)}=15.63, p<0.0001$; Fig. $\left.4 B 1, B 2\right)$. This is consistent with GABA-B receptors located on glutamate terminals being activated by GABA spillover. Additional control experiments further support this scenario, showing that very low concentrations of CRF (30 nM; which typically potentiated responses) reduced EPSCs when CGP55845 was substituted with the GABA reuptake blocker NO-711 $(10 \mu \mathrm{M})(30 \mathrm{nM}$ CRF + NO-711: $17 \pm 11 \%$ decrease relative to baseline at $20-25 \mathrm{~min} ; 30$ nM CRF: $47 \pm 8 \%$ increase relative to baseline at 20-25 min; CRF + NO-711 vs CRF: $t_{(8)}=6.944, p<0.0001$; data not shown).

Given an involvement of GABA-B receptors, the ability of CRF-R2 to facilitate GABA release was examined (Fig. 4C). Electrically evoked IPSCs mediated by GABA-A receptors were blocked completely by picrotoxin $(100 \mu \mathrm{M})$. Application of the CRF-R2 agonist UCN-II (300 nM) potentiated IPSCs and shifted the PPR toward depression (EPSC amplitude with UCN-II: $37 \pm$ $6 \%$ increase from baseline; PPR with UCN-II: $44 \pm 11 \%$ decrease relative to pre-UCN-II; $t_{(7)}=4.664 ; p=0.0023$; Fig. $\left.4 D 1, D 2\right)$. Parallel experiments were conducted to measure CRF-R2mediated changes in the spontaneous release of GABA onto GABA-A receptors. UCN-II (300 nM) increased the frequency of spontaneous IPSCs ( $p=0.0008$; Kolmogorov-Smirnov test; Fig. $4 E, F 1)$. The mean frequency of spontaneous IPSCs shifted from
$4.9 \mathrm{~Hz}$ to $8.1 \mathrm{~Hz}$ at $10 \mathrm{~min}$ and $8.2 \mathrm{~Hz}$ at $20 \mathrm{~min}$ (control vs 10 min: $t_{(10)}=3.090 ; p=0.0114$; Fig. 4F2) and shifted the interevent interval distribution curve significantly to the left at $10 \mathrm{~min}$ and 20 min of application. The same treatment did not alter spontaneous IPSC amplitudes $(p=0.14$; Kolmogorov-Smirnov test; Fig. $4 E, F 1$; from $19.1 \pm 2.3 \mathrm{pA}$ at $10 \mathrm{~min}$ to $18.1 \pm 3.3 \mathrm{pA}$ at 20 min; control vs 10 min: $t_{(10)}=0.9336 ; p=0.3725$, not significant; Fig. 4F2). Collectively, the results above suggest that CRF-R2 activation increases the release probability of GABA onto VTA dopamine neurons. These experiments demonstrate that CRF-R2 indirectly inhibits glutamate terminals by increasing GABA release and activating presynaptic GABA-B receptors.

Because the inhibition mediated by CRF-R2 occurs at higher concentrations of CRF and displays a slower rate of onset, and the potentiation caused by CRF-R1 was not changed by blockade or activation of CRF-R2, it appears that two separate CRF mechanisms regulate presynaptic release of glutamate onto dopamine neurons. Therefore, under control conditions, CRF regulates dopamine neuron excitability via a heterosynaptic CRF-R1/R2mediated mechanism of action involving glutamate and GABA terminals.

An animal model of cocaine self-administration and reinstatement to study CRF-R2

Previous studies in rats indicate that VTA CRF levels are increased during footshock-induced reinstatement, and this relapse-like event requires both activation of VTA dopamine neurons and a poorly understood interaction between cueconditioned glutamate responses and CRF-R2 (Wang et al., 2005, 2007). To investigate this association, the effect of CRF-R2 stimulation on EPSCs and IPSCs was measured after 10-14 d of cocaine self-administration and extinction training $(7 \mathrm{~d})$, with or 
A1

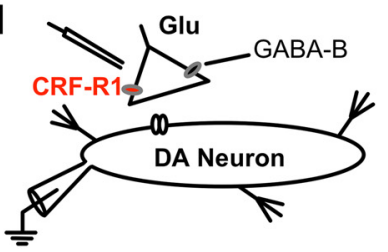

GABA-B antagonist: CGP
B1

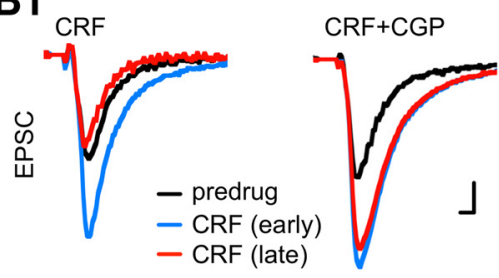

B2

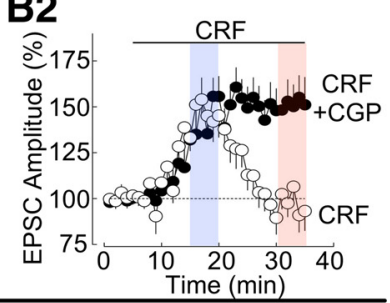

C

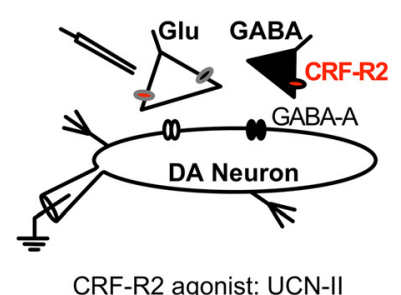

D1 Paired Pulse

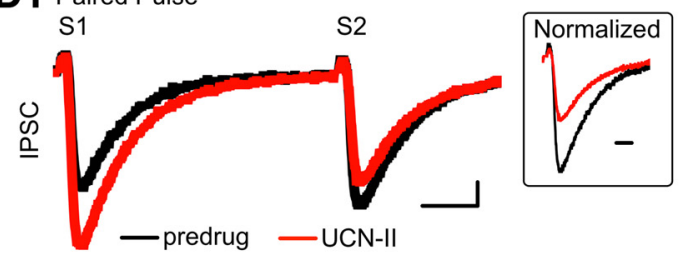

D2

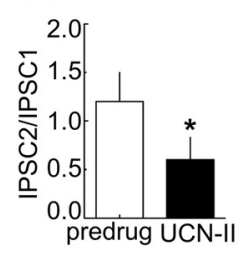

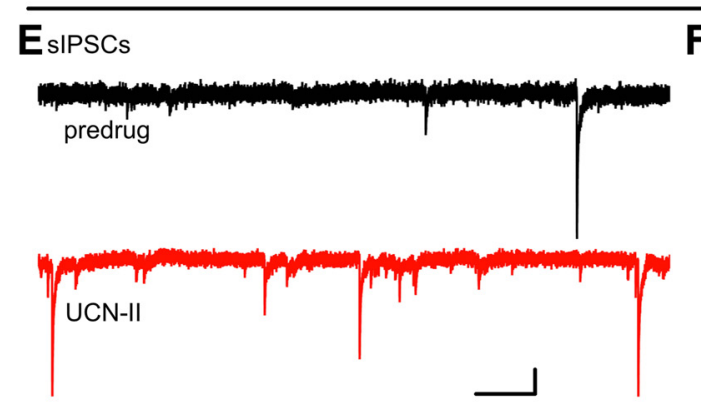

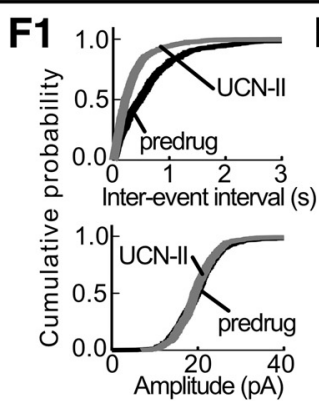

F2
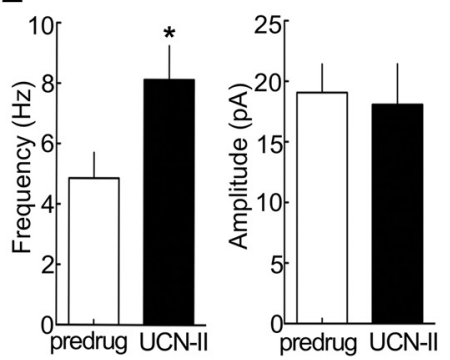

Figure 4. CRF-R2 stimulation reduces EPSCS by promoting GABA release. A, Simplified VTA circuit diagram. The hypothesized location of CRF-R1 is shown. B1, Left, Sample AMPA receptor EPSCS showing application of $100 \mathrm{~nm}$ CRF potentiated EPSCs during the early time period but inhibited EPSCs during later time periods. Right, Similar current traces in a different cell showing that inclusion of the GABA-B receptor antagonist CGP55845 (CGP; $10 \mu \mathrm{m}$ ) prevented the CRF attenuation of the EPSC. Calibration: $100 \mathrm{pA}, 1 \mathrm{~ms}$. B2, Time course summarizing the effect of CGP on the late-phase CRF attenuation (sample size for CRF and CRF + CGP: $n=8$ cells, 4 rats per group). C, Simplified VTA circuit diagram. In this and subsequent figures, black triangles represent GABAergic synaptic terminals. The hypothesized location of CRF-R2 in relation to presynaptic GABA-B receptors on glutamatergic terminals is shown. D1, Left, Sample IPSC traces evoked with paired-pulse stimulation showing application of the CRF-R2 agonist UCN-II (100 nM) potentiates GABA-A receptor-mediated IPSCS. Inset, The second EPSC (S2) after normalization showing a commensurate shift of the PPR of an IPSC toward facilitation in the presence of $100 \mathrm{~nm}$ UCN-II. Calibration: S1/S2, 50 pA, $10 \mathrm{~ms}$; inset, $5 \mathrm{~ms}$. D2, Bar graph noting that the mean PPR of IPSCS shifts toward facilitation during CRF-R2 activation. ${ }^{*} p=0.0023$ ( $n=8$ cells, 4 rats). E, The frequency of sIPSCs is potentiated by UCN-II (100 nM). Calibration: $50 \mathrm{pA}, 0.5 \mathrm{~s}$. F1, Analysis of sIPSCs illustrates that UCN-II (100 nM) altered the interevent interval distribution curve (top, Kolmogorov-Smirnov test, $p=0.0008$ ) but did not alter the cumulative probability plot for sIPSC amplitude (bottom, Kolmogorov-Smirnov test, $p=$ 0.14). $F 2$, Bar graph summary of sIPSCs (sample size: $n=11$ cells, 7 rats). UCN-II (100 nM) altered the average sIPSC frequency (left; $\left.{ }^{*} p=0.0114\right)$, but not the average sIPSC amplitude (right; $p=$ 0.3725 , not significant).

without reinstatement (yohimbine plus cue) (Fig. 5). Similarly treated yoked-saline animals served as controls. Yohimbine was selected as a chemical stressor because it reliably produces anxiety responses and reinstatement of drug seeking in humans and animals (Stine et al., 2002; Lee et al., 2004; Shepard et al., 2004). The relevance of this model is detailed previously (Feltenstein and See, 2006; See and Waters, 2010). In cocaine-treated rats, yohimbine combined with cues reinstated drug seeking over controls (saline: $8 \pm 2$ lever presses; yohimbine + cue: $73 \pm 8$ lever presses; $t_{(30)}=26.24 ; p<0.0001 ;$ Fig. $\left.5 D\right)$. In control rats, yohimbine did not stimulate lever pressing ( $11 \pm 3$ lever presses; Fig. $5 D)$. Animals were killed immediately (within $15 \mathrm{~min}$ ) after reinstatement for electrophysiology experiments.

\section{Cocaine self-administration and extinction training: diminished regulation by CRF-R2}

Control (yoked-saline) and cocaine self-administration or selfadministration with extinction animals were killed immediately after behavioral training (Fig. 5B). Brain slices were prepared to determine whether this treatment produces lasting adaptations in CRF-R2 function. AMPA receptor-mediated EPSCs and GABA-A receptor IPSCs were measured during application of the CRF-R2 agonist UCN-II (300 nM; Fig. 6). For an overall summary of the resulting physiology responses in cocaine selfadministration and extinction tissue, see Figure 6A2.

In control slices from yoked-saline animals, the CRF-R2 agonist UCN-II reduced EPSCs and potentiated IPSCs as predicted (Fig. 6B,D). The magnitude and time course of control EPSC/ IPSC currents resembled responses in naive animals (shown in Figs. $2 C$ and $4 D 1$ ). UCN-II control responses at the $\mathrm{d} 25$ death (when the matching cocaine self-administration ended) and the d40 death (when matching cocaine self-administration with extinction animals were killed) did not differ statistically (EPSCs $\mathrm{d} 25$ vs $\mathrm{d} 40: t_{(28)}=1.246 ; p=0.2231$, not significant; IPSCs $\mathrm{d} 25 \mathrm{vs}$ $\mathrm{d} 40: t_{(22)}=1.460 ; p=0.1585$, not significant). Thus, control data for these two time points were grouped. Individual ANOVAs (one-way repeated measures) indicated a significant effect of UCN-II on EPSC or IPSC amplitudes in control slices (EPSCs: $48 \pm 9 \%$ decrease relative to baseline; $F_{(20,360)}=29.17 ; p<$ 0.0001; Fig. $6 B$; IPSCs: $41 \pm 5 \%$ increase relative to baseline, $F_{(19,266)}=8.624 ; p<0.0001$; Fig. $\left.6 D\right)$.

However, in tissue from rats killed after cocaine self-administration or the extinction period after cocaine self-administration, the UCN-II responses were absent. The diminished UCN-II responses at d25 (immediately after chronic cocaine selfadministration) and $\mathrm{d} 40$ (immediately after self-administration 
A

\begin{tabular}{lll} 
Non-contingent & \multicolumn{2}{c}{ Self-administration (and controls) } \\
\cline { 3 - 3 } Chronic, & Single & Chronic SA \\
IP & Session & Chronic SA + extinct. \\
& & Chronic SA + extinct. \\
& & + yohimbine
\end{tabular}

B Timeline of behavior and brain slices:

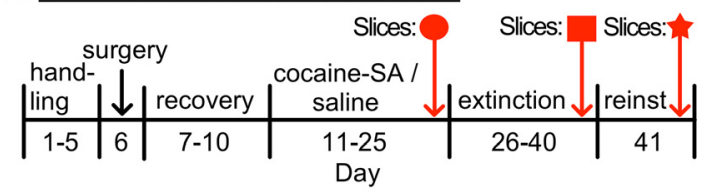

C Operant training: active lever
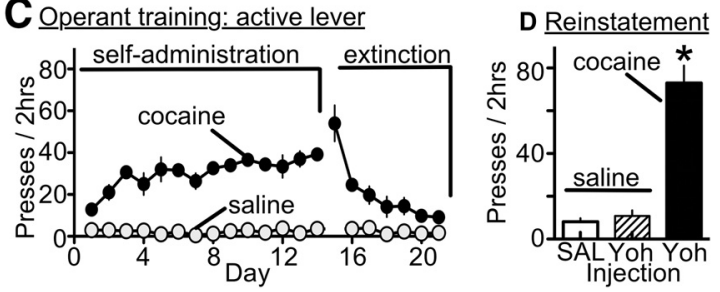

Figure 5. Behavioral treatments in a rat model of cocaine self-administration and reinstatement. $\boldsymbol{A}$, Summary schematic of the different modes of cocaine exposure. $\boldsymbol{B}$, Experimental timeline of procedures, including cocaine self-administration, extinction training, and reinstatement testing with cues and yohimbine $(2.5 \mathrm{mg} / \mathrm{kg}$, i.p.). See Materials and Methods for surgery and cocaine self-administration details. Animals were killed for brain slice experiments after self-administration, extinction training, or reinstatement testing. C, Summary graph showing that, during self-administration, rats receiving cocaine learned to press the active lever and later extinguish self-administration responses during extinction training, whereas yokedsaline groups did not lever press. D, Bar graphs showing yohimbine plus cues induced robust reinstatement of drug seeking in cocaine-experienced (treated) rats, but not yoked-saline (control) rats treated with an injection of saline (SAL) or yohimbine (Yoh). ${ }^{*} p<0.0001$ (paired $t$ test).

with $14 \mathrm{~d}$ of extinction) death were nearly identical; thus, data from treated animals at these two time points were grouped (UCN-II d25 vs d40: $t_{(32)}=1.730 ; p=0.2231$, not significant). Individual ANOVAs (one-way repeated measures) indicated nonsignificant changes by UCN-II (EPSCs: $9 \pm 7 \%$ decrease relative to baseline, $F_{(19,342)}=1.108, p=0.3408$; Fig. $6 B$; IPSCs: $6 \pm$ $7 \%$ decrease relative to baseline, $F_{(19,304)}=0.9631, p=0.5051$, ns; Fig. $6 D$ ). This adaptation persisted and was observed during longer extinction training or withdrawal periods as well (EPSCs at $21 \mathrm{~d}$ extinction: $13 \pm 22 \%$ decrease relative to baseline, $t_{(6)}=$ $1.101 ; p=0.3131$, not significant; IPSCs at $21 \mathrm{~d}$ extinction: $8 \pm$ $14 \%$ increase relative to baseline, $t_{(6)}=0.6793 ; p=0.5223$, not significant; $45 \mathrm{~d}$ homecage withdrawal EPSCs: $16 \pm 19 \%$ decrease relative to baseline, $t_{(6)}=0.6793 ; p=0.5223$, not significant; $45 \mathrm{~d}$ homecage withdrawal IPSCs: $6 \pm 11 \%$ increase relative to baseline, $t_{(6)}=0.5308 ; p=0.6146$, not significant; data not shown). This action of cocaine was robust, as even short-term contingent exposures produced similar adaptations (single cocaine selfadministration + cue session: EPSCs, $13 \pm 17 \%$ decrease relative to baseline, $t_{(12)}=0.3332, p=0.7477$, not significant; IPSCs, $14 \pm 19 \%$ decrease relative to baseline, $t_{(12)}=0.9530 ; p=0.3774$, not significant). Similar observations were apparent with noncontingent cocaine injections as well $(15 \mathrm{mg} / \mathrm{kg}$, i.p. once per day, $7 \mathrm{~d}$; EPSCs, $5 \pm 16 \%$ decrease relative to baseline, $t_{(6)}=1.123$; $p=0.2835$, not significant; IPSCs, $6 \pm 16 \%$ decrease relative to baseline, $t_{(6)}=0.6576 ; p=0.5352$, not significant; data not shown). Thus, cocaine experience diminishes CRF-R2 function in VTA dopamine neurons.

Potential causes for the decline in UCN-II CRF-R2 sensitivity were evaluated. One possibility was that, in animals with a history of cocaine self-administration, the release probability of GABA was maximal, resulting in a ceiling effect beyond which UCN-II would not further potentiate. Consistent with this notion, IPSCs in slices from cocaine self-administration animals in extinction displayed paired-pulse facilitation, rather than the paired-pulse depression observed in control tissue (control: $1.25 \pm 0.13$; cocaine self-administration: $0.69 \pm 0.15 ; t_{(14)}=2.308 ; p=0.0368$; Fig. 6E1,E2). Moreover, the frequency of mIPSCs measured in the presence of TTX was considerably greater in slices from treated animals (cocaine-self-administration: $3.6 \pm 0.19 \mathrm{~Hz}$; control: $1.2 \pm 0.14 \mathrm{~Hz} ; t_{(14)}=6.574 ; p<0.0001$; Fig. 6E1,E2). The amplitude of mIPSCs in slices from control and cocaine self-administration animals in extinction was similar, indicating that postsynaptic response had not been altered (cocaine-selfadministration: $39.46 \pm 0.19 \mathrm{pA}$; control: $42 \pm 15 \mathrm{pA} ; t_{(11)}=$ $0.3483 ; p=0.7341$, not significant). These observations are consistent with an increase in the release probability of GABA under resting conditions, resulting in a ceiling effect.

Elevated GABA release may potentiate GABA-B receptor signaling. Therefore, the action of the GABA-B receptor antagonist CGP $55845(10 \mu \mathrm{M})$ was also evaluated in animals with a history of cocaine self-administration and extinction. Whereas CGP 55845 application did not alter EPSCs in experiments from yoked saline animals, it potentiated EPSCs after cocaine selfadministration or extinction. Individual ANOVAs (one-way repeated measures) revealed significant effects of CGP (saline: $1 \pm 11 \%$ increase relative to baseline, $F_{(29,174)}=0.5709, p=$ 0.9619 , not significant; cocaine self-administration with and without extinction: $44 \pm 12 \%$ increase relative to baseline, $t_{(25,150)}=11.19, p<0.0001$; Fig. $\left.6 C\right)$. This CGP action indicates that a tonic activation of GABA-B receptors after cocaine selfadministration and extinction depresses glutamate release. This previously unreported change in the CRF-R2 response may operate in addition to the previously observed LTP and potentiation of EPSCs after cocaine self-administration (Chen et al., 2008; Bowers et al., 2010). Thus, under operant conditions, chronic cocaine self-administration produces a lasting change in CRF-R2 function in the VTA, paralleled by tonic activation of presynaptic GABA-B receptors on glutamate terminals.

Three other potential causes for the decline in UCN-II sensitivity were evaluated but ultimately rejected as unlikely. First, alterations in postsynaptic receptor function seemed doubtful because both control and treated (cocaine self-administration with and without extinction) tissue produced similar size currents during bath application of AMPA or GABA (AMPA $1 \mu \mathrm{M}$ : control $267 \pm 29 \mathrm{pA}$ vs treated $244 \pm 33 \mathrm{pA}, t_{(14)}=1.167, p=$ 0.2628 , not significant; GABA $100 \mu \mathrm{M}$ : control $210 \pm 16 \mathrm{pA}$ vs treated $241 \pm 29 \mathrm{pA}, t_{(10)}=1.169, p=0.2697$, not significant; data not shown), and there was no change in the amplitude of the mIPSCs as mentioned above. Second, repeated exposure to psychostimulants can decrease neurotransmitter release by heightening presynaptic tone on inhibitory adenosine autoreceptors (Bonci and Williams, 1996; Fiorillo and Williams, 2000). However, this was not the case here because the A1 receptor antagonist DPCPX alone did not alter responses in either group of animals, suggesting that, under resting conditions, little basal tone exists on these synapses. That is, DPCPX did not alter EPSCs (yokedsaline: $4 \pm 17 \%$ decrease relative to baseline; cocaine selfadministration with and without extinction: $6 \pm 9 \%$ increase relative to baseline; $t_{(8)}=1.218, p=0.2581$, not significant; data not shown). Nor did DPCPX alter IPSCs (yoked-saline: $7 \pm 11 \%$ decrease relative to baseline; cocaine self-administration with and without extinction: $13 \pm 15 \%$ decrease relative to baseline; $t_{(7)}=1.345, p=0.2205$, not significant; data not shown). UCN-II sensitivity was not altered by coapplication of the A1 receptor 
A1

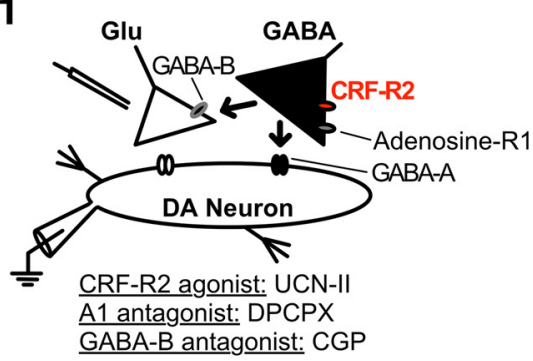

A2

Summary of overall physiology responses

during different treatments compared to

saline controls

\begin{tabular}{ccc} 
Group & $\begin{array}{l}\text { Glutamate } \\
\text { tone }\end{array}$ & $\begin{array}{c}\text { GABA } \\
\text { tone }\end{array}$ \\
\hline Cocaine-SA & $\downarrow$ & $\uparrow$ \\
$\begin{array}{l}\text { Cocaine-SA } \\
+ \text { Extinction }\end{array}$ & $\downarrow$ & $\uparrow$
\end{tabular}

Self-administration / +Extinction: Glutamate
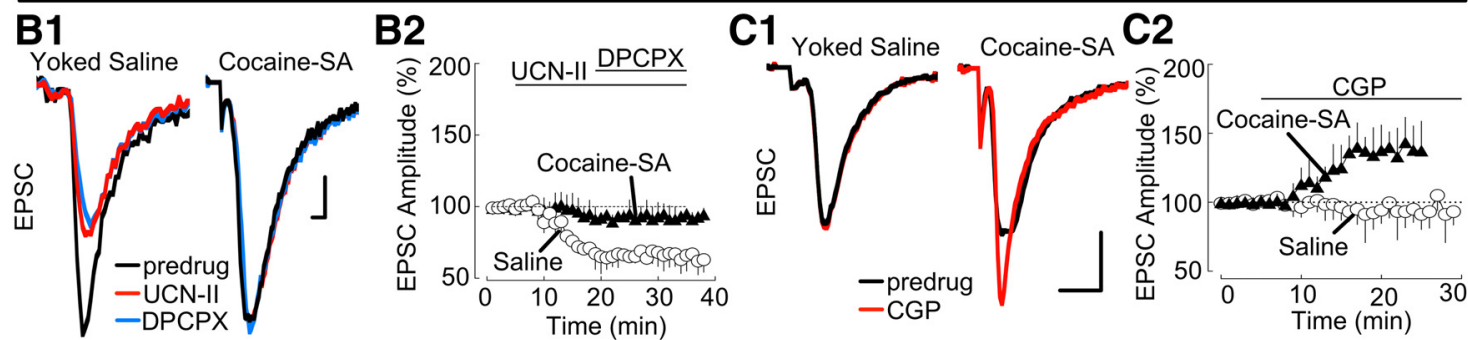

Self-administration / +Extinction: GABA
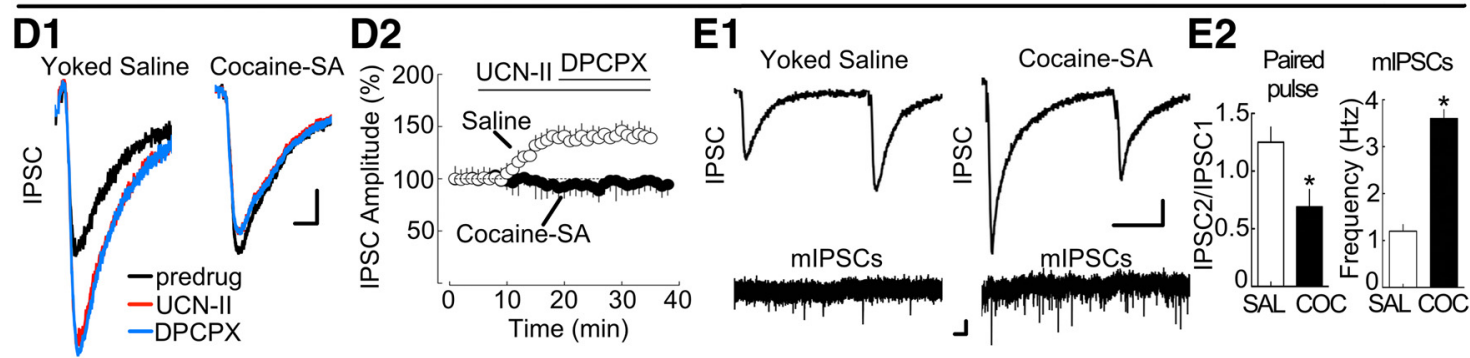

Figure 6. Cocaine self-administration and extinction: diminished CRF-R2 regulation of EPSCS and IPSCs after cocaine exposure. A1, Simplified VTA circuit diagram. The hypothesized location of adenosine receptors is shown. A2, Table summarizing overall physiology responses in tissue from treated rats. B1, Sample traces showing UCN-II (UCN-II; $100 \mathrm{nM}$ ) attenuated EPSCs in tissue from yoked saline-treated rats (left), but not in tissue from rats that had undergone cocaine self-administration or extinction (right). Subsequent blockade of adenosine receptors with DPCPX (200 nm) produced no further change in EPSCs. Calibration: 50 pA, $1 \mathrm{~ms}$. B2, Corresponding summary time course of EPSC amplitudes (\% of baseline, mean \pm SEM), indicating that CRF-R2 activation does not alter EPSCs after cocaine self-administration and extinction. Sample sizes: saline-treated ( $n=19$ cells, 13 rats); self-administration ( $n=24$ cells, 15 rats). C1, Sample traces during blockade of GABA-B receptors. CGP $55845(10 \mu \mathrm{m})$ potentiated EPSCs in self-administration or extinction tissue (right), but not in tissue from yoked saline-treated rats (left). Calibration: $100 \mathrm{pA}, 2$ ms. C2, Corresponding summary time course of EPSC amplitude (\% of baseline, mean \pm SEM; saline- and cocaine-treated: $n=7$ cells, 4 or 5 rats per group). D1, Sample traces showing UCN-II (100 nm) potentiates IPSCs in tissue from yoked saline-treated rats (left), but not self-administration or extinction (right) rats. DPCPX (200 nm) did not alter IPSCs. Calibration: 75 pA, 1 ms. D2, Corresponding summary time course of IPSC amplitude (\% of baseline, mean \pm SEM; saline-treated: $n=15$ cells, 8 rats; self-administration: $n=17$ cells, 9 rats). E1, Sample IPSCs measured by paired-pulse stimulation (top; calibration: 100 pA, 20 ms) and sIPSCs (bottom; calibration: 10 pA, $1 \mathrm{~s}$ ) in experiments from (left) yoked saline and (right) treated rats. E2, Bar graphs summarizing changes in the paired-pulse depression (left; ${ }^{*} p=0.0368$; PPR sample size: control, $n=8$ cells, 4 rats; cocaine self-administration, $n=5$ cells, 3 rats) and the frequency of sIPSCs after cocaine self-administration and extinction (right; ${ }^{*} p<0.0001$; IPSC sample size: control, $n=6$ cells, 3 rats; cocaine-SA, $n=7$ cells, 3 rats).

antagonist DPCPX (200 nM). Individual ANOVAs (one-way repeated measures) of EPSCs with UCN-II indicated no effect of DPCPX (cocaine self-administration with and without extinction: $5.0 \pm 11 \%$ decrease relative to pre-DPCPX, $F_{(14,322)}=$ $1.018 ; p=0.4345$, not significant; yoked-saline: $4.6 \pm 8 \%$ decrease relative to pre-DPCPX, $F_{(17,306)}=0.6655 ; p=0.8362$, not significant; Fig. 6B2). A similar ANOVA of IPSCs in UCN-II also indicated no effect of DPCPX (cocaine self-administration with and without extinction: $7 \pm 11 \%$ decrease relative to pre$\mathrm{DPCPX}, F_{(15,240)}=1.117 ; p=0.3415$, not significant; yokedsaline, $2.73 \pm 6 \%$ increase relative to pre-DPCPX, $F_{(14,196)}=$ $0.7757 ; p=0.6947$, not significant; Fig. 6D2). Third, increased basal CRF tone on CRF-R2 could occlude the UCN-II agonist response, but this was not supported by experiments showing that application of a CRF-R2 antagonist alone did not alter EPSCs or IPSCs (K414: EPSCs, $11 \pm 14 \%$ decrease relative to baseline, $t_{(6)}=0.5858, p=0.5794$, not significant; IPSCs, $10 \pm 12 \%$ increase relative to baseline, $t_{(8)}=1.023, p=0.3362$, not significant; data not shown).
In summary, a cellular adaptation in the function of CRF-R2 emerges. The modification is unrelated to alterations in postsynaptic receptors, adenosine receptor tone, or tonic CRF-R2 activation. The adaptation may reflect a long-lasting increase in the probability of GABA release triggered by a prior cocaine experience.

Yohimbine plus cue-induced reinstatement: CRF-R2 potentiates EPSCs and adenosine tone emerges

Reinstatement testing was performed in three groups of animals: (1) yoked-saline (control) rats receiving a saline injection; (2) yoked-saline (control) rats treated with yohimbine; and (3) cocaine self-administration (treated) rats treated with yohimbine and cues. Behavioral responses to saline or yohimbine $(2.5 \mathrm{mg} /$ $\mathrm{kg}$, i.p.) are summarized in Figure 5. At the end of the session, animals were killed and brain slices were prepared. GABA-A receptor-mediated IPSCs and AMPA receptor-mediated EPSCs were measured to evaluate CRF-R2 function. Because responses between control groups were comparable, results from yoked- 

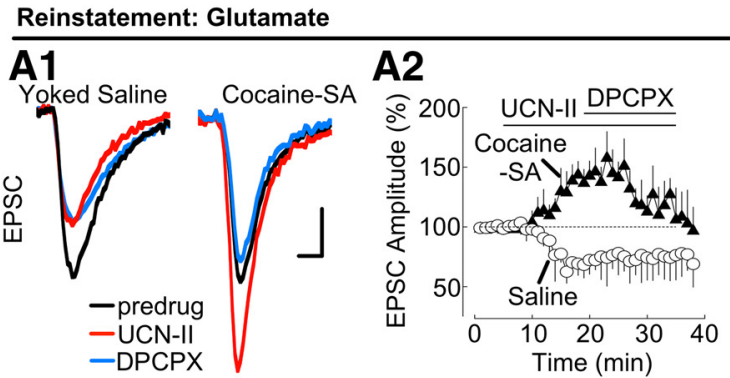

Reinstatement: GABA
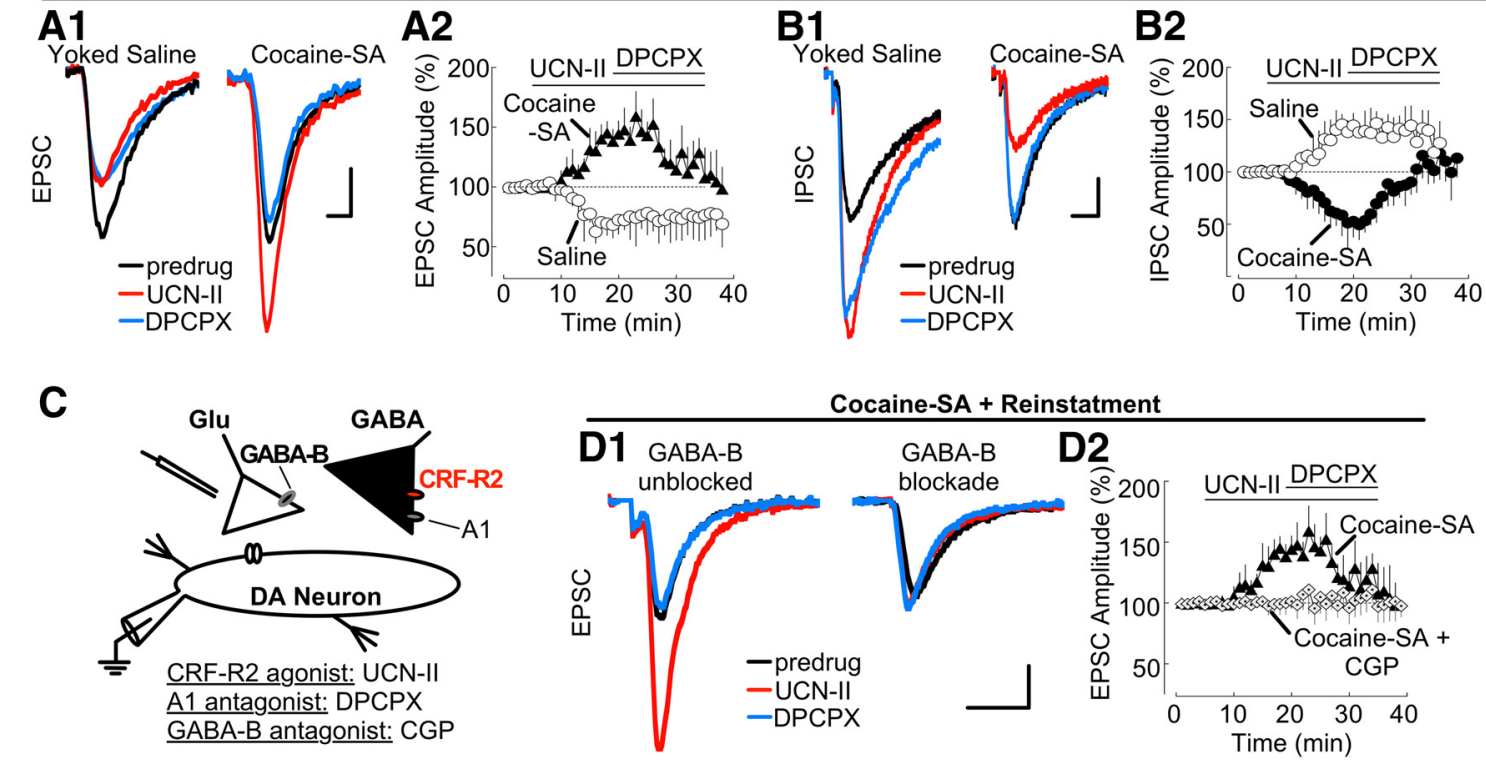

Figure 7. Blockade of adenosine receptors reverses adaptations in CRF-R2 function that potentiate glutamate EPSCs during yohimbine plus cue-induced reinstatement. A1, Sample traces showing CRF-R2 activation with UCN-II (100 nM) attenuated EPSCS in experiments from saline control rats (yoked-saline treated with yohimbine; left) but potentiated EPSCS after cocaine self-administration and reinstatement (right). In cocaine self-administration and reinstatement tissue (but not control slices), blockade of adenosine receptors with DPCPX (200 nM) attenuated EPSC. Calibration: 50 pA, 1 ms. A2, Corresponding summary time course (\% of baseline, mean \pm SEM). Sample size: saline ( $n=13$ cells, 6 rats); cocaine self-administration ( $n=10$ cells, 6 rats). B1, Sample traces showing that UCN-II (100 nM) potentiated IPSC in experiments from yoked saline-treated rats (left) but attenuated IPSCs after cocaine self-administration and reinstatement (right). Subsequent block of A1 adenosine receptors with DPCPX (200 nM) produced no further change in control rat IPSCs but increased IPSC amplitude back to basal levels after cocaine self-administration and reinstatement. Calibration: $50 \mathrm{pA}, 5 \mathrm{~ms}$. B2, Summary time course of IPSC amplitude (\% of baseline, mean \pm SEM) confirms the reversal in the response to CRF-R2 activation after cocaine self-administration and reinstatement, as well as the increase after A1 adenosine receptor block. Sample size: saline $(n=13$ cells, 7 rats); cocaine-SA ( $n=10$ cells, 8 rats). C, Simplified VTA circuit diagram. The hypothesized location of CRF-R2 in relation to presynaptic GABA-B receptors on glutamatergic terminals and A1 receptors on GABAergic terminals is shown. D1, Sample traces showing CRF-R2 activation with UCN-II (100 nM) potentiates EPSCs; action reversed by blockade of adenosine receptors with DPCPX (200 nM). The UCN-II and DPCPX action is blocked by the GABA-B receptor antagonist CPG $55845(10 \mu \mathrm{M})$. Calibration: $50 \mathrm{pA}, 5 \mathrm{~ms}$. D2, Corresponding summary time course of IPSC amplitude (\% of baseline, mean \pm SEM). Sample size: saline ( $n=9$ cells, 5 rats); cocaine-SA ( $n=10$ cells, 6 rats).

saline animals treated with saline are reported, but only yokedsaline + yohimbine responses are depicted (Fig. $7 A, B$ ).

Behavioral responses of yoked saline animals were as predicted, as neither control group showed increased lever pressing with yohimbine/cue presentation (Fig. 5D). EPSC and IPSC responses to UCN-II (300 nM) were evaluated in tissue from control animals. Yohimbine injections did not significantly alter UCN-II sensitivity in control slices (EPSCs: yoked-saline + saline group, $28 \pm 17 \%$ decrease relative to baseline, $F_{(20,140)}=2.007$; $p<0.0001$; yoked-saline + yohimbine, $23 \pm 13 \%$ decrease relative to baseline; $F_{(20,240)}=5.712 ; p<0.0001$; Fig. 7A2; IPSCs: yoked-saline + saline group, $55 \pm 16 \%$ increase relative to baseline, $F_{(20,160)}=6.111 ; p<0.0001$; yoked-saline + yohimbine, $47 \pm 11 \%$ increase relative to baseline; $F_{(20,240)}=8.723 ; p<$ 0.0001; Fig. 7B2). Nor did yohimbine treatment alter predrug (baseline) amplitudes of IPSC and EPSCs (EPSCs: yoked-saline + saline group, $234 \pm 37 \mathrm{pA}$ vs yoked-saline + yohimbine, $254 \pm$ $67 \mathrm{pA}, t_{(19)}=1.563, p=0.1345$, not significant; IPSCs: yokedsaline + saline group, $233 \pm 43 \mathrm{pA}$ vs yoked-saline + yohimbine, $277 \pm 39 \mathrm{pA}, t_{(20)}=1.674, p=0.1096$, not significant). Thus, these results indicate that physiology control responses resembled those seen in naive animals, and yohimbine treatment itself did not produce measurable differences in CRF-R2 function.

As observed in earlier studies, yohimbine treatment with cues reinstated lever pressing in animals with a prior history of cocaine self-administration (Fig. 5D) (Feltenstein and See, 2006). In slices from these animals, the response to CRF-R2 activation was substantially altered and differed from responses in tissue from control animals treated with yohimbine. UCN-II now augmented
EPSCs and attenuated IPSCs (EPSCs: $56 \pm 19 \%$ increase relative to baseline, $F_{(20,180)}=6.332, p<0.0001$; Fig. 7A2; IPSCs: $46 \pm$ $12 \%$ decrease relative to baseline, $F_{(20,180)}=9.333, p<0.0001$; Fig. 7B2). These UCN-II responses were reversed completely by the A1 receptor antagonist DPCPX at $200 \mathrm{~nm}$ (EPSCs: return to $7 \pm 15 \%$ of baseline, $F_{(18,162)}=4.485, p<0.0001$; Fig. 7A2; IPSCs: return to $10 \pm 14 \%$ of baseline, $F_{(16,144)}=3.852$, $p<$ 0.0001; Fig. 7B2). A similar ANOVA (one-way repeated measures) analysis in yoked-saline indicated no actions of DPCPX (EPSC: $F_{(18,216)}=1.002, p=0.4591$, not significant; Fig. 7A2; IPSC: $F_{(14,168)}=1.146, p=0.3215$, not significant; Fig. $\left.7 B 2\right)$. DPCPX responsiveness in tissue from animals with a history of cocaine exposure suggests the emergence of a strong inhibitory tone at adenosine receptors. Notably, if the preceding UCN-II challenge was omitted, DPCPX had no measureable effect in tissue from treated animals (EPSCs: $6 \pm 9 \%$ decrease from baseline, $t_{(5)}=0.8501 p=0.4573$, not significant; IPSCs: $7 \pm 8 \%$ decrease from baseline, $t_{(8)}=1.184, p=0.2703$, data not shown), suggesting that adenosine tone is associated with CRF-R2 activation. In experiments in tissue from control animals treated with yohimbine, DPCPX did not alter UCN-II responses (EPSCs: $11 \pm 16 \%$ increase from baseline, $t_{(8)}=1.359 ; p=0.2111$; IPSCs: $13 \pm 18 \%$ increase from baseline, $t_{(5)}=0.8672 ; p=0.4255$; data not shown).

The ability of CRF-R2 to potentiate EPSCs after reinstatement required functional GABA-B receptors. The potentiation of EPSCs by the CRF-R2 agonist UCN-II (300 nM) was blocked by inclusion of GABA-B receptor antagonist CPG $55845(10 \mu \mathrm{M})$ (UCN-II: $61 \pm 15 \%$ increase from baseline, $F_{(20,180)}=6.332 ; p<$ 0.0001; Fig. 7D; UCN-II + CGP: $8 \pm 13 \%$ increase from baseline; 
$F_{(19,152)}=1.222 ; p=0.2466$, not significant; Fig. $\left.7 D\right)$. This indicates that, after reinstatement, CRF-R2 increased EPSCs as a result of a reduction of tonic GABA-dependent inhibition. Subsequent block of A1 adenosine receptors with DPCPX (200 $\mathrm{nM}$ ) attenuated the UCN-II response (UCN-II + DPCPX: $42.4 \pm$ $2.6 \%$ decrease from pre-DPCPX, $F_{(16,144)}=4.507, p<0.0001$; Fig. 7D2). Thus, after reinstatement, blockade of adenosine receptors increases GABA tone to inhibit the CRF-R2 action. In contrast, blockade of GABA-B receptors with CPG 55845 prevented both the CRF-R2 increase in EPSCs and the attenuation produced by DPCPX (UCN-II + CGP: $8 \pm 13 \%$ increase from baseline; $F_{(19,152)}=1.222 ; p=0.2466$, not significant; UCN-II + CGP + DPCPX: $9 \pm 11 \%$ increase from pre-DPCPX; $F_{(17,136)}=$ $0.5510 ; p=0.9214$, not significant; Fig. $7 D)$. These findings indicate that, after yohimbine plus cue-induced reinstatement, CRF-R2 activation mediates a reduction in tonic GABA inhibition via an adenosine A1 receptor-dependent mechanism.

Together, these results suggest that, after cocaine selfadministration and extinction training, CRF-R2 regulation of GABA transmission is diminished. After yohimbine plus cueinduced reinstatement, CRF-R2 function reverses, inhibiting GABA transmission and thereby enhancing glutamate output. Under these conditions, blockade of adenosine receptors reversed the actions of CRF-R2, indicating an underlying role for inhibitory adenosine autoreceptors on GABAergic terminals in the CRF-R2 potentiation of glutamate neurotransmission after reinstatement (Fig. 8).

\section{Discussion}

This study demonstrates that, in dopamine neurons, the stress hormone CRF acts on two receptor subtypes to potentiate glutamate EPSCs at lower concentrations (3-30 nM) but attenuate glutamate EPSCs at higher concentrations (300 nM) (Fig. 8). The CRF potentiation relies on CRF-R1 activation, a direct action on glutamate terminals. A separate indirect action of CRF reduces EPSCs, via binding to CRF-R2 and facilitation of GABA release to activate presynaptic GABA-B receptors on glutamate terminals. Thus, in control tissue, CRF shapes glutamate release to fine-tune neuronal excitability by a concerted heterosynaptic action. This bimodal action of CRF would influence any mechanism involving glutamate release onto AMPA receptors within the VTA.

In animals with a history of cocaine self-administration, this mechanism shifts in a fundamental way. First, during extinction training, the CRF-R2 attenuation is prevented (occluded), due to increased GABA release. Second, in contrast to its actions in drug-naive animals where CRF-R2 stimulation decreases glutamate release, activation of CRF-R2 receptors increases glutamate EPSCs after yohimbine plus cue-induced reinstatement. This combination removes an essential GABA brake on glutamate transmission and in response dopamine neuron excitability and VTA output would be expected to increase (rather than decrease) during stressful situations when CRF-R2 is activated. This finding reveals a principal difference in the maintenance of the two types of CRF-regulated synapses after chronic cocaine selfadministration. The underlying cause is a CRF-R2-related decline in GABA transmission, triggered by activation of presynaptic inhibitory adenosine receptors. Therefore, after a history of cocaine self-administration and exposure to a stressful experience, the CRF response is dominated by facilitation of glutamate neurotransmission.

In this study, we investigated the actions of CRF on EPSCs mediated by AMPA receptors and IPSCs mediated by GABA-A receptors. Anatomical evidence indicates that the dendrites of

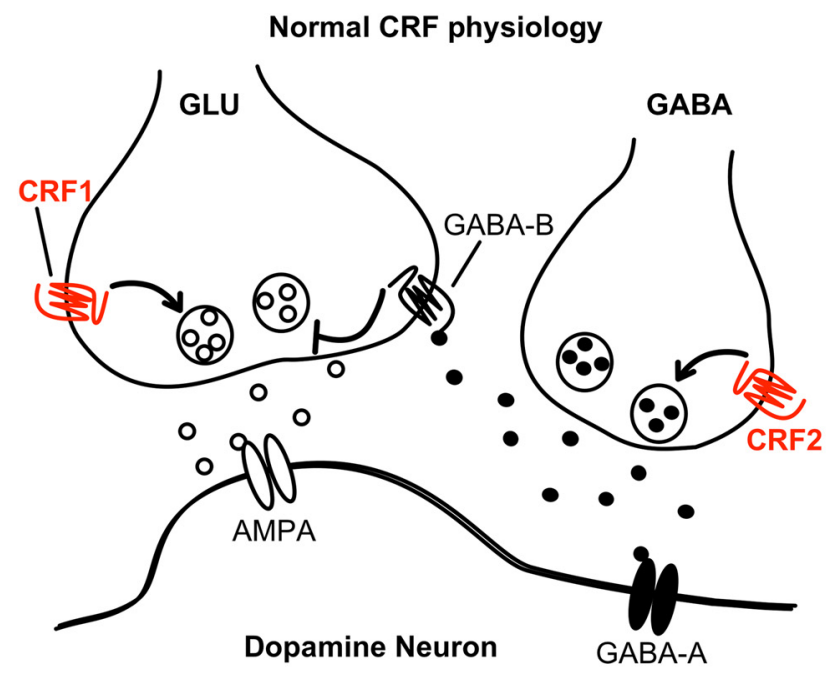

CRF physiology after stress-induced reinstatment of cocaine-seeking

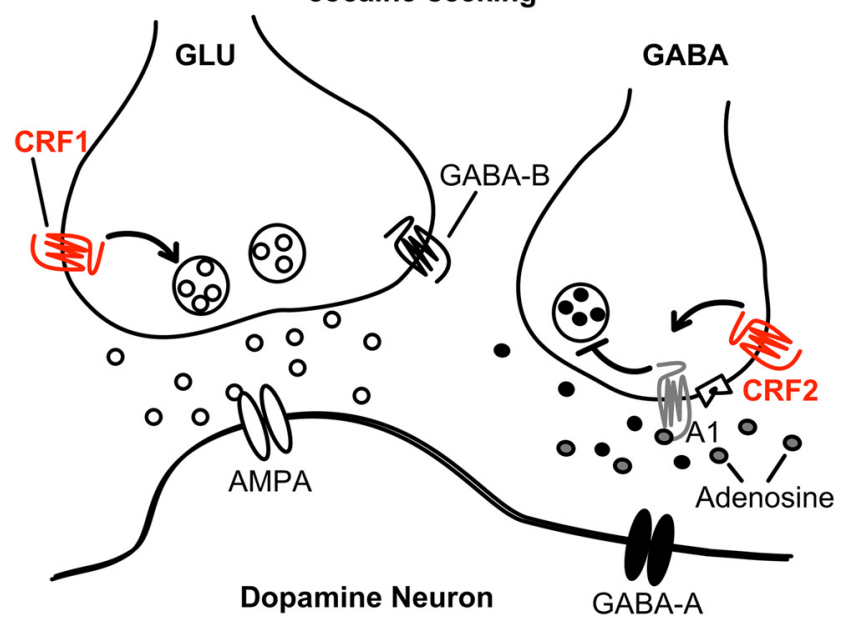

Figure 8. Regulation of glutamate release onto VTA dopamine neurons via CRF. Top, Under normal conditions, presynaptic CRF-R1 potentiates glutamate release onto AMPA receptors on dopamine neurons. CRF-R2 activation potentiates GABA release, which activates postsynaptic $G A B A-A$ receptors and presynaptic GABA-B receptors on glutamatergic terminals. Bottom, After cocaine-self-administration, GABA release is potentiated, suppressing glutamate release. After yohimbine plus cue-induced reinstatement, CRF-R2 activation decreases GABA release via an adenosine receptor-dependent mechanism.

dopamine neurons possess AMPA and GABA-A receptors and receive both glutamate and GABA connections (Omelchenko and Sesack, 2007, 2009; Jalabert et al., 2011). Glutamatergic inputs arise from numerous sources, including the stria terminalis (Colussi-Mas et al., 2007; Omelchenko and Sesack, 2007), where CRF signaling potentiates glutamate release (Nobis et al., 2011). Inhibitory GABAergic inputs arise from both intrinsic VTA GABA interneurons and extrinsic sources, such as the RMTg or nucleus accumbens. Intrinsic VTA GABA neurons synapse with dendritic shafts of dopamine cells, whereas extrinsic GABA terminals form axosomatic contacts (Omelchenko and Sesack, 2009; Jalabert et al., 2011). GABAergic terminals from the nucleus accumbens are more sensitive to presynaptic inhibition by adenosine receptor activation than either VTA interneurons or terminals arising from the rostromedial tegmental nucleus (RMTg) (Matsui et al., 2014). 


\section{Regulation of glutamate by a CRF-R1 and CRF-R2 heterosynaptic mechanism}

Biophysical measurements indicated that CRF-R1/R2 are presynaptic and localized to different types of terminals (Manabe et al., 1993; Zucker, 2013). These observations were not appreciated before and differ from the postsynaptic CRF-R2 potentiation of NMDA responses reported previously (Ungless et al., 2003; Hahn et al., 2009). In VTA, amygdala, and hippocampus, GABA-B mediated heterosynaptic depression regulates excitatory synapses (Isaacson et al., 1993; Manzoni and Williams, 1999; Fiorillo and Williams, 2000; Fu and Neugebauer, 2008). In the present experiments, CRF-R2 attenuation of EPSCs required activation of GABA-B receptors. When the spatial range of synaptically released GABA was increased by blocking GABA reuptake, low concentrations of CRF attenuated (rather than potentiated) EPSCs. Thus, CRF regulates glutamate EPSCs via a heterosynaptic CRF-R1/R2 mechanism requiring GABA spillover onto presynaptic GABA-B receptors. These physiological data are consistent with anatomical studies showing CRF in both presumed excitatory and inhibitory terminals contacting VTA dopamine neuron dendrites (Tagliaferro and Morales, 2008). These presynaptic actions of CRF-R2 are distinct from previously reported postsynaptic CRF-R1 actions (Korotkova et al., 2006; Riegel and Williams, 2008; Wanat et al., 2008; Beckstead et al., 2009).

The data above indicate that CRF can shape glutamate transmission under control conditions. The heterosynaptic CRF$\mathrm{R} 1 / \mathrm{R} 2$ mechanism is interesting in light of studies associating CRF-R1 with anxiogenesis and CRF-R2 with anxiolysis (Kishimoto et al., 2000; Risbrough et al., 2004; Ji and Neugebauer, 2008). In this manner, under normal conditions, circulating or synaptically released CRF likely optimizes glutamate transmission for appropriate responses to a changing environment.

\section{Diminished CRF-R2 function after cocaine self- administration and extinction}

To better understand the ability of CRF to limit stress responsivity, CRF-R2 was examined under conditions known to alter its function: drug self-administration and stress-induced relapse modeled by yohimbine injections (Wise, 2009; Wise and Morales, 2010). Stressors promote drug taking and reinstatement after withdrawal by increasing glutamate release in the VTA (Wang et al., 2005). Visual and/or auditory stimuli that serve as cues to the predicted presence of cocaine can trigger glutamate release in animals with a history of cocaine self-administration. This probably does not occur to the same extent in animals repeatedly treated with noncontingent cocaine because cocaine delivery has not been associated with operant cues. Recent data suggest a need for a strong pairing between the drug and a cue (Liu and Weiss, 2002; Chen et al., 2008), and glutamate release may serve to establish the "expectancy" of cocaine (Wise, 2009). In cocaine-experienced rats, stressors also increase glutamate release in the VTA, which in turn triggers reinstatement of cocaineseeking (Wang et al., 2007). This adaptation in the regulation of VTA glutamate release by CRF is enduring (Wang et al., 2005). Infusion of antagonists for CRF-R2 into the VTA blocks reinstatement if cues are presented in conjunction with the stress exposure (Liu and Weiss, 2002; Wang et al., 2007). Thus, CRF-R2 takes on an important (but poorly understood) role during relapse, which may be most apparent after cue-contingent cocaine self-administration.

During extinction training, adaptations in GABA release weaken the CRF-R2 regulation of EPSCs or IPSCs, despite GABA receptor sensitivity measurements remaining constant. Further- more, there was no evidence for existing CRF-R2 tone as determined by the effect of the CRF-R2 antagonist K41498 in control or cocaine-experienced slices. However, in these slices, the PPR of the IPSC shifted from facilitation to depression, consistent with enhanced GABA release after drug exposure (Bonci and Williams, 1996; Melis et al., 2002). Presumably, a maximal release of GABA occludes subsequent potentiation by CRF-R2. Thus, in tissue from rats with a history of cocaine self-administration, CRF-R2 function is diminished.

\section{CRF-R2, reinstatement of cocaine seeking, and adenosine receptors}

After reinstatement, CRF-R2 function reverses to potentiate EPSCs and attenuate IPSCs (Fig. 8). The switch in responses required $\mathrm{A} 1$ adenosine receptors but was absent in controls treated with yohimbine. Thus, the underlying adaptation is a response to chronic cocaine self-administration and not a direct pharmacological action of yohimbine. A CRF-R2-mediated switch in the regulation of glutamate transmission (from inhibition to facilitation) was also reported in the lateral septum (Liu et al., 2005). Similar shifts in GABA transmission occur in VTA dopamine neurons. For instance, activation of cAMP signaling attenuated (rather than potentiated) GABA-B IPSCs during withdrawal from chronic morphine treatment (Bonci and Williams, 1996), and antagonism of A1 adenosine receptors or manipulation of adenosine metabolism prevented these actions (Bonci and Williams, 1996). Thus, in drug-treated animals, increased metabolism of cAMP increased tone on inhibitory adenosine receptors (Bonci and Williams, 1996). The present results show that, after reinstatement (without additional administration of cocaine), UCN-II produced opposite responses in EPSCs and IPSCs that could be reversed by blockade of adenosine receptors. This suggests that, during reinstatement, elevated levels of CRF may activate Gs-coupled CRF-R2 to increase extracellular concentrations of adenosine and reverse the regulation of GABA release.

As a stress hormone, the actions of CRF constitute a cellular basis for relapse-relevant changes in glutamate transmission in the VTA (Wang et al., 2005, 2007; Blacktop et al., 2011). After chronic cocaine exposure, CRF may synergize at CRF-R1/R2, as both receptors are implicated in stress reinstatement (Erb et al., 1998; Lu et al., 2001, 2003; Wang et al., 2007; Blacktop et al., 2011). The CRF-R2 potentiation of glutamate we observed is probably contextual in nature (Wang et al., 2005, 2007), although additional experiments are required to understand the relative contribution of yohimbine. Like drug-conditioned cues, the anxiogenic yohimbine induces drug-seeking behavior (Shepard et al., 2004; Feltenstein and See, 2006). In combination, yohimbine and cues produce additive increases in reinstatement (Feltenstein and See, 2006) that may better model the human condition. Nevertheless different operant conditions (Blacktop et al., 2011), the absence of drug cues, or different types of stress (Joëls and Baram, 2009) produce additional adaptations independent of CRF-R2 or GABA-B receptors.

In conclusion, CRF-R2 modulation of GABA transmission contributes to the regulation of glutamate release in VTA dopamine cells. The mechanism involves a heterosynaptic depression mediated via presynaptic GABA-B receptors. These physiological mechanisms change after cocaine experience. CRF-R2 regulation of GABA release is degraded by cocaine experience, and after cue plus yohimbine induced drug seeking reverses function to potentiate glutamate responses (Fig. 8). The result is a persistent change in the regulation of glutamate release in the VTA and therefore of dopamine neuron output. 


\section{References}

Bale TL, Contarino A, Smith GW, Chan R, Gold LH, Sawchenko PE, Koob GF, Vale WW, Lee KF (2000) Mice deficient for corticotropin-releasing hormone receptor-2 display anxiety-like behaviour and are hypersensitive to stress. Nat Genet 24:410-414. CrossRef Medline

Bannon MJ, Wolf ME, Roth RH (1983) Pharmacology of dopamine neurons innervating the prefrontal, cingulate and piriform cortices. Eur J Pharmacol 92:119-125. CrossRef Medline

Beckstead MJ, Gantz SC, Ford CP, Stenzel-Poore MP, Phillips PE, Mark GP, Williams JT (2009) CRF enhancement of GIRK channel-mediated transmission in dopamine neurons. Neuropsychopharmacology 34: 1926-1935. CrossRef Medline

Blacktop JM, Seubert C, Baker DA, Ferda N, Lee G, Graf EN, Mantsch JR (2011) Augmented cocaine seeking in response to stress or CRF delivered into the ventral tegmental area following long-access self-administration is mediated by CRF receptor type 1 but not CRF receptor type 2. J Neurosci 31:11396-11403. CrossRef Medline

Bonci AA, Williams JTJ (1996) A common mechanism mediates long-term changes in synaptic transmission after chronic cocaine and morphine. Neuron 16:9-12. CrossRef Medline

Bowers MS, Chen BT, Bonci A (2010) AMPA receptor synaptic plasticity induced by psychostimulants: the past, present, and therapeutic future. Neuron 67:11-24. CrossRef Medline

Chen BT, Bowers MS, Martin M, Hopf FW, Guillory AM, Carelli RM, Chou JK, Bonci A (2008) Cocaine but not natural reward self-administration nor passive cocaine infusion produces persistent LTP in the VTA. Neuron 59:288-297. CrossRef Medline

Colussi-Mas J, Geisler S, Zimmer L, Zahm DS, Bérod A (2007) Activation of afferents to the ventral tegmental area in response to acute amphetamine: a double-labelling study. Eur J Neurosci 26:1011-1025. CrossRef Medline

Coste SC, Kesterson RA, Heldwein KA, Stevens SL, Heard AD, Hollis JH, Murray SE, Hill JK, Pantely GA, Hohimer AR, Hatton DC, Phillips TJ, Finn DA, Low MJ, Rittenberg MB, Stenzel P, Stenzel-Poore MP (2000) Abnormal adaptations to stress and impaired cardiovascular function in mice lacking corticotropin-releasing hormone receptor-2. Nat Genet 24: 403-409. CrossRef Medline

Deutch AY, Roth RH (1990) The determinants of stress-induced activation of the prefrontal cortical dopamine system. Prog Brain Res 85:367-402; discussion 402-403. Medline

Erb S, Shaham Y, Stewart J (1998) The role of corticotropin-releasing factor and corticosterone in stress- and cocaine-induced relapse to cocaine seeking in rats. J Neurosci 18:5529-5536. Medline

Feltenstein MW, See RE (2006) Potentiation of cue-induced reinstatement of cocaine-seeking in rats by the anxiogenic drug yohimbine. Behav Brain Res 174:1-8. CrossRef Medline

Fiorillo CD, Williams JT (2000) Selective inhibition by adenosine of mGluR IPSPs in dopamine neurons after cocaine treatment. J Neurophysiol 83: 1307-1314. Medline

Ford CP, Mark GP, Williams JT (2006) Properties and opioid inhibition of mesolimbic dopamine neurons vary according to target location. J Neurosci 26:2788-2797. CrossRef Medline

Fu Y, Neugebauer V (2008) Differential mechanisms of CRF1 and CRF2 receptor functions in the amygdala in pain-related synaptic facilitation and behavior. J Neurosci 28:3861-3876. CrossRef Medline

Fuchs RA, Evans KA, Parker MP, See RE (2004) Differential involvement of orbitofrontal cortex subregions in conditioned cue-induced and cocaineprimed reinstatement of cocaine seeking in rats. J Neurosci 24:66006610. CrossRef Medline

Gallagher JP, Orozco-Cabal LF, Liu J, Shinnick-Gallagher P (2008) Synaptic physiology of central CRH system. Eur J Pharmacol 583:215-225. CrossRef Medline

Hahn J, Hopf FW, Bonci A (2009) Chronic cocaine enhances corticotropinreleasing factor-dependent potentiation of excitatory transmission in ventral tegmental area dopamine neurons. J Neurosci 29:6535-6544. CrossRef Medline

Isaacson JS, Solís JM, Nicoll RA (1993) Local and diffuse synaptic actions of GABA in the hippocampus. Neuron 10:165-175. CrossRef Medline

Jalabert M, Bourdy R, Courtin J, Veinante P, Manzoni OJ, Barrot M, Georges F (2011) Neuronal circuits underlying acute morphine action on dopamine neurons. Proc Natl Acad Sci U S A 108:16446-16450. CrossRef Medline

Ji G, Neugebauer V (2007) Differential effects of CRF1 and CRF2 receptor antagonists on pain-related sensitization of neurons in the central nucleus of the amygdala. J Neurophysiol 97:3893-3904. CrossRef Medline

Ji G, Neugebauer V (2008) Pro- and anti-nociceptive effects of corticotropinreleasing factor (CRF) in central amygdala neurons are mediated through different receptors. J Neurophysiol 99:1201-1212. CrossRef Medline

Joëls M, Baram TZ (2009) The neuro-symphony of stress. Nat Rev Neurosci 10:459-466. CrossRef Medline

Kishimoto T, Radulovic J, Radulovic M, Lin CR, Schrick C, Hooshmand F, Hermanson O, Rosenfeld MG, Spiess J (2000) Deletion of crhr2 reveals an anxiolytic role for corticotropin-releasing hormone receptor-2. Nat Genet 24:415-419. CrossRef Medline

Korotkova TM, Brown RE, Sergeeva OA, Ponomarenko AA, Haas HL (2006) Effects of arousal- and feeding-related neuropeptides on dopaminergic and GABAergic neurons in the ventral tegmental area of the rat. Eur J Neurosci 23:2677-2685. CrossRef Medline

Lee B, Tiefenbacher S, Platt DM, Spealman RD (2004) Pharmacological blockade of alpha2-adrenoceptors induces reinstatement of cocaineseeking behavior in squirrel monkeys. Neuropsychopharmacology 29: 686-693. CrossRef Medline

Liu J, Yu B, Orozco-Cabal L, Grigoriadis DE, Rivier J, Vale WW, ShinnickGallagher P, Gallagher JP (2005) Chronic cocaine administration switches corticotropin-releasing factor 2 receptor-mediated depression to facilitation of glutamatergic transmission in the lateral septum. J Neurosci 25:577-583. CrossRef Medline

Liu X, Weiss F (2002) Additive effect of stress and drug cues on reinstatement of ethanol seeking: exacerbation by history of dependence and role of concurrent activation of corticotropin-releasing factor and opioid mechanisms. J Neurosci 22:7856-7861. Medline

Lu L, Liu D, Ceng X (2001) Corticotropin-releasing factor receptor type 1 mediates stress-induced relapse to cocaine-conditioned place preference in rats. Eur J Pharmacol 415:203-208. CrossRef Medline

Lu L, Liu Z, Huang M, Zhang Z (2003) Dopamine-dependent responses to cocaine depend on corticotropin-releasing factor receptor subtypes. J Neurochem 84:1378-1386. CrossRef Medline

Manabe T, Wyllie DJ, Perkel DJ, Nicoll RA (1993) Modulation of synaptic transmission and long-term potentiation: effects on paired pulse facilitation and EPSC variance in the CA1 region of the hippocampus. J Neurophysiol 70:1451-1459. Medline

Manzoni OJ, Williams JT (1999) Presynaptic regulation of glutamate release in the ventral tegmental area during morphine withdrawal. J Neurosci 19:6629-6636. Medline

Marino MJ, Wittmann M, Bradley SR, Hubert GW, Smith Y, Conn PJ (2001) Activation of group I metabotropic glutamate receptors produces a direct excitation and disinhibition of GABAergic projection neurons in the substantia nigra pars reticulata. J Neurosci 21:7001-7012. Medline

Matsui A, Jarvie BC, Robinson BG, Hentges ST, Williams JT (2014) Separate GABA afferents to dopamine neurons mediate acute action of opioids, development of tolerance, and expression of withdrawal. Neuron 82:1346-1356. CrossRef Medline

Melis M, Camarini R, Ungless MA, Bonci A (2002) Long-lasting potentiation of GABAergic synapses in dopamine neurons after a single in vivo ethanol exposure. J Neurosci 22:2074-2082. Medline

Nobis WP, Kash TL, Silberman Y, Winder DG (2011) $\beta$-Adrenergic receptors enhance excitatory transmission in the bed nucleus of the stria terminalis through a corticotrophin-releasing factor receptor-dependent and cocaine-regulated mechanism. Biol Psychiatry 69:1083-1090. CrossRef Medline

Omelchenko N, Sesack SR (2007) Glutamate synaptic inputs to ventral tegmental area neurons in the rat derive primarily from subcortical sources. Neuroscience 146:1259-1274. CrossRef Medline

Omelchenko N, Sesack SR (2009) Ultrastructural analysis of local collaterals of rat ventral tegmental area neurons: GABA phenotype and synapses onto dopamine and GABA cells. Synapse 63:895-906. CrossRef Medline

Riegel AC, Lupica CR (2004) Independent presynaptic and postsynaptic mechanisms regulate endocannabinoid signaling at multiple synapses in the ventral tegmental area. J Neurosci 24:11070-11078. CrossRef Medline

Riegel AC, Williams JT (2008) CRF facilitates calcium release from intracellular stores in midbrain dopamine neurons. Neuron 57:559-570. CrossRef Medline

Risbrough VB, Hauger RL, Roberts AL, Vale WW, Geyer MA (2004) Corticotropin-releasing factor receptors CRF1 and CRF2 exert both ad- 
ditive and opposing influences on defensive startle behavior. J Neurosci 24:6545-6552. CrossRef Medline

See RP, Waters RP (2010) Pharmacologically-induced stress: a cross-species probe for translational research in drug addiction and relapse. Am J Transl Res 3:81-89. Medline

Shepard JD, Bossert JM, Liu SY, Shaham Y (2004) The anxiogenic drug yohimbine reinstates methamphetamine seeking in a rat model of drug relapse. Biol Psychiatry 55:1082-1089. CrossRef Medline

Stine SM, Southwick SM, Petrakis IL, Kosten TR, Charney DS, Krystal JH (2002) Yohimbine-induced withdrawal and anxiety symptoms in opioid-dependent patients. Biol Psychiatry 51:642-651. CrossRef Medline

Tagliaferro P, Morales M (2008) Synapses between corticotropin-releasing factor-containing axon terminals and dopaminergic neurons in the ventral tegmental area are predominantly glutamatergic. J Comp Neurol 506: 616-626. Medline

Timpl P, Spanagel R, Sillaber I, Kresse A, Reul JM, Stalla GK, Blanquet V, Steckler T, Holsboer F, Wurst W (1998) Impaired stress response and reduced anxiety in mice lacking a functional corticotropin-releasing hormone receptor 1. Nat Genet 19:162-166. CrossRef Medline

Ungless MA, Singh V, Crowder TL, Yaka R, Ron D, Bonci A (2003) Corticotropin-releasing factor requires $\mathrm{CRF}$ binding protein to potentiate NMDA receptors via CRF receptor 2 in dopamine neurons. Neuron 39: 401-407. CrossRef Medline

Wanat MJ, Hopf FW, Stuber GD, Phillips PE, Bonci A (2008)
Corticotropin-releasing factor increases mouse ventral tegmental area dopamine neuron firing through a protein kinase $\mathrm{C}$-dependent enhancement of Ih. J Physiol 586:2157-2170. CrossRef Medline

Wang B, Shaham Y, Zitzman D, Azari S, Wise RA, You ZB (2005) Cocaine experience establishes control of midbrain glutamate and dopamine by corticotropin-releasing factor: a role in stress-induced relapse to drug seeking. J Neurosci 25:5389-5396. CrossRef Medline

Wang B, You ZB, Rice KC, Wise RA (2007) Stress-induced relapse to cocaine seeking: roles for the $\mathrm{CRF}(2)$ receptor and CRF-binding protein in the ventral tegmental area of the rat. Psychopharmacology 193:283-294. CrossRef Medline

Williams JT, Fiorillo CD (1998) Glutamate mediates an inhibitory postsynaptic potential in dopamine neurons. Nature 394:78-82. CrossRef Medline

Wise RA (2009) Ventral tegmental glutamate: a role in stress-, cue-, and cocaine-induced reinstatement of cocaine-seeking. Neuropharmacology 56:174-176. CrossRef Medline

Wise RA, Morales M (2010) A ventral tegmental CRF-glutamate-dopamine interaction in addiction. Brain Res 1314:38-43. CrossRef Medline

Wolfart J, Neuhoff H, Franz O, Roeper J (2001) Differential expression of the small-conductance, calcium-activated potassium channel SK3 is critical for pacemaker control in dopaminergic midbrain neurons. J Neurosci 21:3443-3456. Medline

Zucker RS (2013) Short-term synaptic plasticity. Annu Rev Neurosci 12:13-31. CrossRef Medline 